\title{
Diffusion and sorption of organic micropollutants in biofilms with varying thicknesses
}

Torresi, Elena; Polesel, Fabio; Bester, Kai; Christensson, Magnus; Smets, Barth F.; Trapp, Stefan; Andersen, Henrik Rasmus; Plósz, Benedek G.

Published in:

Water Research

Link to article, DOI:

10.1016/j.watres.2017.06.027

Publication date:

2017

Document Version

Peer reviewed version

Link back to DTU Orbit

Citation (APA):

Torresi, E., Polesel, F., Bester, K., Christensson, M., Smets, B. F., Trapp, S., Andersen, H. R., \& Plósz, B. G. (2017). Diffusion and sorption of organic micropollutants in biofilms with varying thicknesses. Water Research, 123, 388-400. https://doi.org/10.1016/j.watres.2017.06.027

\section{General rights}

Copyright and moral rights for the publications made accessible in the public portal are retained by the authors and/or other copyright owners and it is a condition of accessing publications that users recognise and abide by the legal requirements associated with these rights.

- Users may download and print one copy of any publication from the public portal for the purpose of private study or research.

- You may not further distribute the material or use it for any profit-making activity or commercial gain

- You may freely distribute the URL identifying the publication in the public portal 
3

4

Diffusion and sorption of organic micropollutants in biofilms with varying thicknesses

5

6

$16 \dagger$ Joint first authors.

17

18

19 *Benedek Gy. Plósz: b.g.plosz@bath.ac.uk

20

**Elena Torresi: elto@env.dtu.dk 

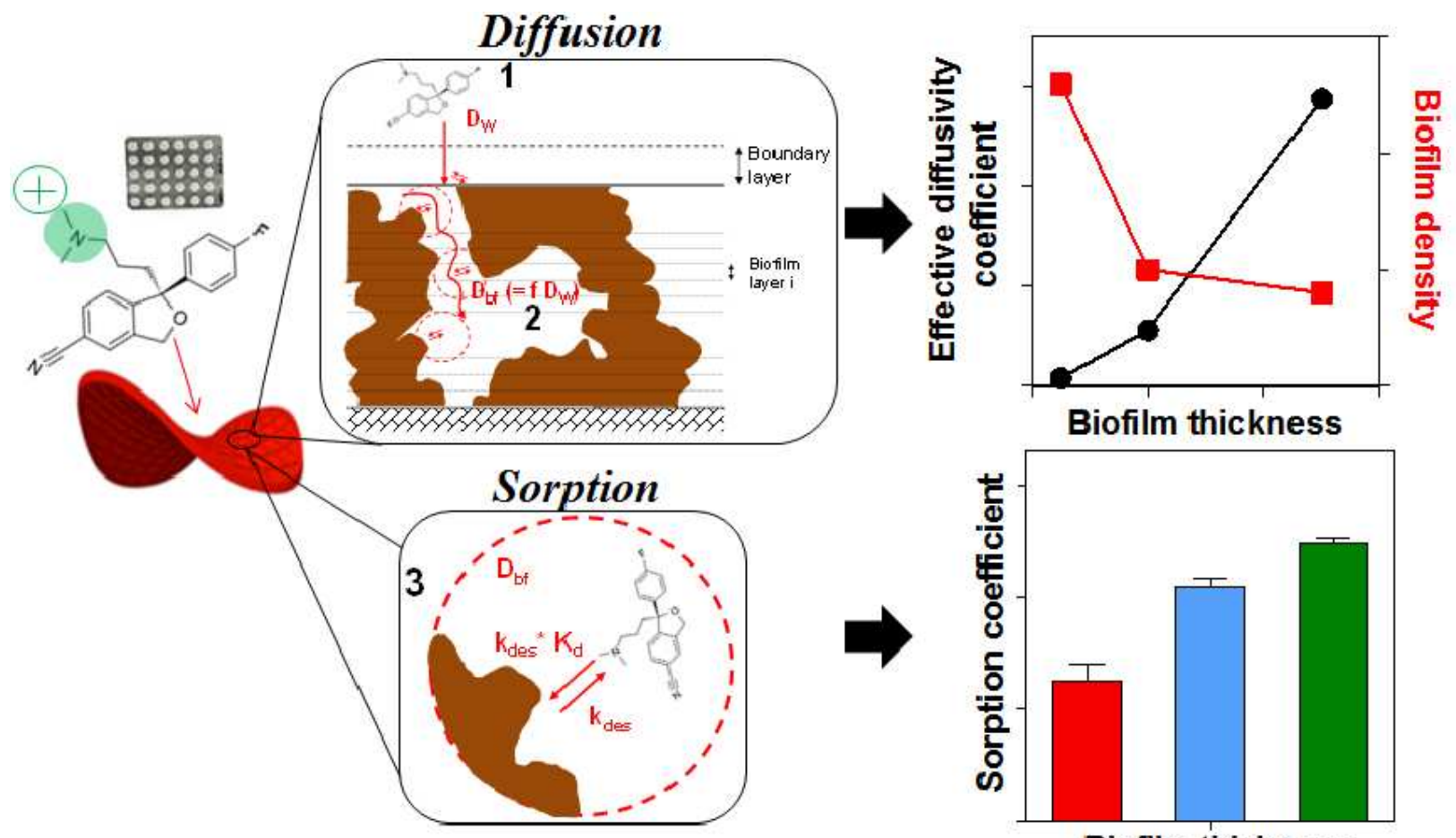

Biofilm thickness 


\section{Abstract}

24 Solid-liquid partitioning is one of the main fate processes determining the removal of 25 micropollutants in wastewater. Little is known on the sorption of micropollutants in biofilms, where molecular diffusion may significantly influence partitioning kinetics. In this study, the diffusion and the sorption of 23 micropollutants were investigated in novel moving bed biofilm reactor $(\mathrm{MBBR})$ carriers with controlled biofilm thickness $(50,200$ and $500 \mu \mathrm{m})$ using targeted

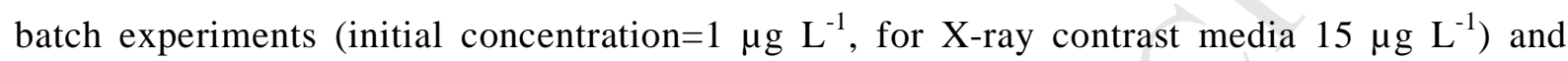
mathematical modelling. We assessed the influence of biofilm thickness and density on the dimensionless effective diffusivity coefficient $f$ (-, equal to the biofilm-to-aqueous diffusivity ratio) and the distribution coefficient $K_{d, e q}\left(\mathrm{~L} \mathrm{~g} \mathrm{~g}^{-1}\right)$. Sorption was significant only for eight positively charged micropollutants (atenolol, metoprolol, propranolol, citalopram, venlafaxine, erythromycin, clarithromycin and roxithromycin), revealing the importance of electrostatic interactions with solids. Sorption equilibria were likely not reached within the duration of batch experiments $(4 \mathrm{~h})$, particularly for the thickest biofilm, requiring the calculation of the distribution coefficient $K_{d, e q}$ based on the approximation of the asymptotic equilibrium concentration $(\mathrm{t}>4 \mathrm{~h}) . K_{d, e q}$ values increased with increasing biofilm thickness for all sorptive micropollutants (except atenolol), possibly due to higher porosity and accessible surface area in the thickest biofilm. Positive correlations between $K_{d, e q}$ and micropollutant properties (polarity and molecular size descriptors) were identified but not for all biofilm thicknesses, thus confirming the challenge of improving predictive sorption models for positively charged compounds. A diffusion-sorption model was developed and calibrated against experimental data, and estimated $f$ values also increased with increasing biofilm thickness. This indicates that diffusion in thinner biofilms may be strongly limited $(f<<0.1)$ by the higher biomass density (lower porosity) compared to thicker biofilms. 
48 Keywords: Pharmaceuticals, wastewater, moving bed biofilm reactor, partitioning, biofilm

49 density, ionizable chemicals

50 


\section{Introduction}

52 In wastewater treatment systems, partitioning of organic micropollutants to solid matrices is one of

53 the mechanisms leading to their removal from the aqueous phase. The extent of partitioning is

54 typically compound-dependent, and is governed by its affinity for organic phase (i.e., hydrophobic

55 partitioning) and/or by electrostatic and other similar interactions between ionized molecules and

56 charged solid surfaces (i.e., non-hydrophobic partitioning) (Franco and Trapp, 2008; Hyland et

57 al., 2012; Ternes et al., 2004; Mackay and Vasudevan, 2012; Polesel et al., 2015).

58 Partitioning describes the distribution of molecules between the aqueous and the solid phase.

59 At equilibrium, sorption and desorption rates are equal, and the ratio of sorbed and dissolved 60 concentrations-normalized to the concentration of solids - is defined as the (linear) solid-

61 liquid partition coefficient $K_{d}$ (expressed in units of $\mathrm{L} \mathrm{kg}^{-1}$ or, alternatively, $\mathrm{L} \mathrm{g}^{-1}$ ) (Joss et al., 62 2006; Ternes et al., 2004). Non-linear expressions (Freundlich and Langmuir isotherms) have 63 been also used to describe partitioning equilibria to account for saturation of solid surfaces or 64 synergistic effects (Delle Site, 2001).

65 Solid-liquid partitioning has been characterized for activated sludge biomass for a high number 66 of pharmaceuticals Considerably less evidence is available for wastewater treatment biofilms, 67 being limited to antibiotics (sulfamethoxazole, erythromycin, ciprofloxacin, tetracycline) and 68 psycho-active drugs (fluoxetine) in biofilters (Wunder et al., 2011) and granules (Alvarino et 69 al., 2015; Shi et al., 2011). Additionally, partitioning kinetics of other organic contaminants 70 (polycyclic aromatic hydrocarbons, estrogens, nonylphenols, biocides) have been assessed for 71 pure culture biofilms (Wicke et al., 2008, 2007) and river biofilms (Headley et al., 1998; 72 Writer et al., 2011).

73 Although considered a fast process, partitioning is influenced by mass transfer limitation 74 through diffusive boundary layers and inside the solid matrices, which likely determines the 
time needed to achieve equilibrium between aqueous and sorbed concentrations (Joss et al., 2004, 2006). While for activated sludge the equilibrium time is sufficiently fast to prevent an empirical evaluation of mass transfer limitation (Joss et al., 2004; Plósz et al., 2010; Barret et al., 2011), molecular diffusion may have a major role in determining partitioning kinetics in biofilms. Biofilm characteristics such as biomass density and porosity have been found to influence intra-biofilm diffusion of a number of organic and inorganic chemical compounds. This effect has been described by introducing a coefficient $f$, defined as the ratio of effective diffusivity in biofilms and in free aqueous media, thus defining diffusivity reduction in biofilms (Fan et al., 1990; Guimerà et al., 2016; Horn and Morgenroth, 2006; Trapp and Matthies, 1998; Zhang and Bishop, 1994a). While $f$ was determined for a number of organic and inorganic chemical compounds, no conclusive evidence currently exists for organic micropollutant diffusion in biofilms, which was therefore investigated in this study.

In our previous work (Torresi et al., 2016), we investigated the biological transformation of pharmaceuticals in nitrifying moving bed biofilm reactors (MBBRs) using novel MBBR carriers (AnoxKaldnes Z-carriers), allowing the control of the biofilm thickness.

In this study, the main objective set was to assess how the diffusion and partitioning of 23 selected pharmaceuticals vary at different biofilm thicknesses $(50,200$ and $500 \mu \mathrm{m})$ and to quantify corresponding single point $K_{d}$ values at environmentally relevant concentration levels. By developing and calibrating a model that describes diffusive transport and partitioning in biofilms, we aimed at elucidating the influence of biofilm thickness on (i) the molecular diffusion of micropollutants within biofilm matrix, described by the dimensionless effective diffusivity coefficient $f$; (ii) the extent of partitioning, described by coefficient $K_{d}$. Additionally, using experimental and modelling results, the influence of biofilm characteristics (porosity, density) and molecular properties (e.g., hydrophobicity, ionization) on the mass 
99 transfer limitation and sorption of micropollutants in biofilms were assessed. 


\section{Model development}

101

102

103

104

105

106

107

108

109

110

111 according to Hayduk and Laudie (1974), although alternative approaches were also tested

112 (Table S1 in Supplementary Information).

113 Transport from the bulk liquid to the biofilm is controlled by the diffusion through a boundary 114 layer, for which the diffusivity was assumed equal to $D_{W, i}$ (Assumption I, Fig 1b). The 115 thickness of the boundary layer, $L_{L}(\mu \mathrm{m})$, was assumed to be equal to $10 \mu \mathrm{m}$ for all the Z116 carriers (Brockmann et al., 2008, see section 1 in SI). In biofilms, molecular diffusivity is 117 reduced compared to free aqueous media (Wanner and Reichert, 1996). This has been 118 attributed to the "tortuosity" of the transport path in biofilms, i.e. the increased (non-linear) 119 path length needed for diffusive transport as compared to free aqueous media (Zhang and 120 Bishop, 1994b). Molecular diffusivity reduction is described by the dimensionless coefficient $121 f$, resulting in Eq. 1:

$122 D_{b f, i}=f \cdot D_{W, i}$
(Eq. 1) 
123 where $D_{b f, i}\left(\mathrm{~m}^{2} \mathrm{~d}^{-1}\right)$ is the effective diffusivity of micropollutants within biofilms and $f(-)$ is

124 always lower than 1 . While $f$ values of $0.5-0.8$ have been assigned for micropollutant diffusion

125 (Ort and Gujer, 2008; Vasiliadou et al., 2014), this parameter is likely to vary significantly

126 depending on the biofilm structure and properties (biofilm thickness, density, porosity and

127 tortuosity).

128 It has previously been shown that biofilm porosity and density can vary over the biofilm depth

129 (Zhang and Bishop, 1994a). In the model, we assume the biofilm as a homogenous porous

130 medium (Assumption II), although we accept that biofilms with different depth can have

131 different average porosities and densities. As a consequence, only one $f$ value was used to

132 describe diffusion reduction into a biofilm with a certain thickness.

133 Sorption/desorption kinetics were described using first-order rate equations (see matrix in Fig.

134 1c). Sorption was considered as an equilibrium process (Assumption III), by attributing an

135 arbitrarily high value to the desorption rate $k_{d e s}$, thereby making diffusion from the bulk

136 aqueous phase and within the biofilm the rate-limiting steps for solid-liquid partitioning. At

137 micropollutant concentration levels targeted in this study (ng $\mathrm{L}^{-1}$ to $\mu \mathrm{g} \mathrm{L}^{-1}$ ), sorption can be

138 considered linear and better described by the distribution coefficient $K_{d}$ (Assumption IV).

139 Based on the presented conceptual approach, a diffusion-sorption model was implemented as

140 one-dimensional biofilm model in Aquasim 2.1 (Reichert, 1994). Design and measured biofilm

141 properties (biofilm thickness, surface area, biomass density, porosity) were used as input to the

142 model (see Table 1). Each biofilm was spatially discretized in 20 completely mixed layers.

143 This allowed solving the generic mass balance equation for dissolved micropollutant

144 concentration $C_{L}\left(\right.$ ng L $\left.{ }^{-1}\right)$ in biofilm (Eq. 2):

$145 \frac{\partial C_{L}}{\partial t}=D_{b f, i} \frac{\partial^{2} C_{L}}{\partial z^{2}}-k_{d e s} K_{d} C_{L} X+k_{d e s} C_{S}$ 
146 (where $X$ is the biomass concentration in biofilm, $\mathrm{g} \mathrm{L}^{-1} ; C_{S}$ is the sorbed micropollutant 147 concentration, $\mathrm{ng} \mathrm{L} \mathrm{L}^{-1} ; C_{L}$ varies with time $\mathrm{t}$ and depth $\mathrm{z}$ ) as a set of ordinary differential 148 equations by using the method of lines (Wanner and Reichert, 1996). According to the 149 diffusion-sorption model, micropollutants undergo equilibrium microscale partitioning as they 150 diffuse through biofilm, in analogy to the approach proposed by Wu and Gschwend (1986).

151 Further details on the conceptual biofilm model, on microscopic mass balances and on the 152 initial conditions are given in the Supplementary Information (section S1 and Figure S1).

\section{$<$ Figure $1>$}

154

\subsection{Calculation of sorption coefficients}

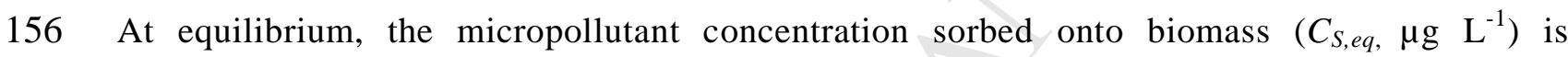
157 proportional to the dissolved concentration $\left(C_{L, e q}, \mu \mathrm{g} \mathrm{L}^{-1}\right)$, and their ratio, normalized by the 158 concentration of solids $\left(X_{\text {biomass }}, \mathrm{g} \mathrm{L}^{-1}\right)$, is used to calculate the sorption coefficient $K_{d, e q}\left(\mathrm{~L} \mathrm{~g}^{-1}\right)$.

159 With negligible transformation, it is commonly assumed (e.g., in activated sludge) that the 160 sorbed concentration is equivalent to the decrease in dissolved concentration $\left(C_{L, 0}-C_{L, e q}\right)$ 161 between the beginning and the end of batch sorption experiments.

162 When considering biofilm systems, transport in biofilm pores, along with sorption, can also 163 determine a decrease of micropollutant concentrations in the bulk phase. Hence, the coefficient

$164 \boldsymbol{K}_{\boldsymbol{d}, \boldsymbol{e q}}\left(\mathrm{L} \mathrm{g}^{-1}\right)$ was defined to describe sorption in Z-carrier biofilms based on mass balance 165 considerations (Eq. 3):

$166 K_{d, e q}=\frac{\left[\frac{C_{L, 0} V_{b u l k}}{V_{b u l k}+V_{b f, w e t}}-\frac{C_{L, e q}\left(V_{b u l k}+V_{P W}\right)}{V_{b u l k}+V_{b f, w e t}}\right]}{C_{L, e q} X_{\text {biomass }}}$ (Eq. 3)

167 where $V_{\text {bulk }}(\mathrm{L})$ denotes the volume of the bulk liquid, $V_{b f, w e t}(\mathrm{~L})$ the volume of wet biofilm 168 (equal to the total surface area of Z-carriers times the defined biofilm thickness) and $V_{P W}(\mathrm{~L})$ 
169 the volume of the pore water in the biofilm matrix, not accounting for cellular water content

170 (see 3.4). The procedure used to derive Eq. 3 is presented in detail in the Supplementary

171 Information (section S3).

172 The 'asymptotic' concentration $C_{L, e q}$, defining true sorption equilibrium, was estimated by

173 fitting measured concentration profiles in batch sorption experiments with a first-order decay

174 equation (Eq. 4)

175

$C_{L}(t)=\left(C_{L, 0}-C_{L, e q}\right) e^{-k t}+C_{L, e q}$

(Eq. 4)

176 In activated sludge, it has been widely accepted that sorption equilibrium can be reached 177 within 0.5-1 h (Ternes et al., 2004; Andersen et al., 2005; Yi and Harper, 2007, Hörsing et al., 178 2011). To verify whether sorption equilibrium was achieved relatively fast (i.e., within the 4179 hour duration of sorption experiments) also in Z-carrier biofilms, the sorption coefficient $\boldsymbol{K}_{\boldsymbol{d}, 4 \boldsymbol{h}}$ $180 \quad\left(\mathrm{~L} \mathrm{~g}^{-1}\right)$ was calculated (Eq. 5):

181

$K_{d, 4 h}=\frac{\left[\frac{C_{L, 0} V_{b u l k}}{V_{b u l k}+V_{b f, w e t}}-\frac{C_{L, 4 h}\left(V_{b u l k}+V_{P W}\right)}{V_{b u l k}+V_{b f, w e t}}\right]}{C_{L, 4 h} X_{\text {biomass }}}$

182 where $C_{L, 4 h}$ is the measured dissolved concentration in bulk aqueous phase at $\mathrm{t}=4 \mathrm{~h}$ (the last 183 measurement in sorption experiments), replacing $C_{L, e q}$ in Eq. 3. Specifically, the 4-hour 184 equilibrium assumption was verified by comparing $K_{d, 4 h}$ and $K_{d, e q}$ and assessing the relative 185 deviation between the two coefficients.

186 As mentioned above, the decrease of bulk micropollutant concentration during sorption 187 experiments with biofilms results from transport in biofilm pores (besides sorption in 188 biofilms). To verify the impact of neglecting mass transfer to biofilm pores on sorption 189 coefficient determination, the sorption coefficient $\boldsymbol{K}_{\boldsymbol{d} \text {,susp }}$ was calculated (Eq. 6):

190

$K_{d, \text { susp }}=\frac{C_{L, 0}-C_{L, e q}}{C_{L, e q} X_{\text {biomass }}}$ 
191 where $C_{L, e q}$ was calculated using Eq. 4. Notably, Eq. 6 is commonly used to describe sorption

192 onto suspended activated sludge, where the effect of porosity is neglected. The comparison

193 between $K_{d, e q}$ and $K_{d, \text { susp }}$ (together with relative deviation the two coefficients) was used to

194 quantify the contribution of transport to biofilm pores, hence the impact of porosity, on the

195 estimated sorption coefficient.

196

$197 \quad 2.3$ Parameter estimation approach

198 The assessment of diffusion and sorption of micropollutants in biofilms consisted of two main

199 consecutive steps performed for each micropollutant and at different biofilm thicknesses: (i)

200 calculation of the coefficient $K_{d, e q}$ (section 2.2); (ii) calibration of the diffusion-sorption model

201 (section 2.1) against experimental data and estimation of the coefficient $f$, which was the only

202 parameters fitted in the model. Estimation of $f$ was performed using the secant model

203 calibration algorithm embedded in Aquasim 2.1. 


\section{Materials and methods}

205

206

207

208

209

210

211

212

213

214

215

216

217

218

219

220

221

222

223

224

225

226

227

\subsection{System description and operation}

Nitrifying MBBRs used in this study have been described elsewhere (Torresi et al., 2016). Briefly, two laboratory-scale nitrifying MBBRs were operated in parallel under continuousflow conditions for approximately 300 days. Z-carriers (AnoxKaldnes AB, Lund, Sweden) were used to obtain biofilm of different thicknesses. Z-carriers have a saddle shaped grid covered surface allowing for biofilm growth only up to the height of the grid wall (Torresi et al., 2016). Three different Z-carriers (named Z50, Z200, and Z500) were used in this study, with the numbers indicating the grid wall height in $\mu \mathrm{m}$ (hence the maximum controlled biofilm thickness). Biofilms were enriched by feeding the MBBRs with effluent wastewater from a local municipal treatment plant (Källby, Lund, Sweden), spiked with ammonium (50 mg L $\mathrm{L}^{-1}$ of $\mathrm{NH}_{4}-\mathrm{N}$ as $\left.\mathrm{NH}_{4} \mathrm{Cl}\right)$ and phosphate $\left(0.5 \mathrm{mg} \mathrm{L}^{-1}\right.$ of $\mathrm{PO}_{4}-\mathrm{P}$ as $\left.\mathrm{KH}_{2} \mathrm{PO}_{4}\right)$. The MBBRs were operated under similar conditions, i.e. hydraulic residence time of $2 \mathrm{~h}$, dissolved oxygen concentration of $4.5 \pm 0.5 \mathrm{mg} \mathrm{L}^{-1}, \mathrm{pH}$ of $7.5 \pm 0.5$ and temperature of $20^{\circ} \mathrm{C}$ (achieved using a thermostat).

\subsection{Sorption batch experiments}

Sorption batch experiments were performed after reaching stable nitrogen removal (Torresi et al., 2016), roughly, around day 300. Prior to batch experiments, the two MBBRs were disconnected and three types of Z-carriers (Z50, Z200, Z500) were manually separated. Subsequently, Z-carriers were left overnight at $4{ }^{\circ} \mathrm{C}$ in a beaker with tap water to allow for desorption of micropollutants possibly sorbed during continuous-flow operation.

Sorption batch experiments were carried out in three 200 -mL glass beakers using filtered $(0.2$ $\mu \mathrm{m}$ Munktell MG/A glass fiber filters) effluent wastewater from Källby treatment plant. Ammonium and nitrate in the feed were at concentration of $<0.5 \mathrm{mgN} \mathrm{L}^{-1}$ and $6 \mathrm{mgN} \mathrm{L}^{-1}$, 
228

229

230

231

232

233

234

235

236

237

238

239

240

241

242

243

244

245

246

247

248

249

250

251

respectively, while organic carbon concentration was lower than $35 \mathrm{mgCOD} \mathrm{L}^{-1}$, mostly in inert form.

The biomass concentration in the three glass beakers was adjusted to $0.8 \mathrm{~g} \mathrm{~L}^{-1}$ based on attached biomass concentration measurements for the different carriers and adjusting the number of carriers accordingly (56 carriers for Z50, 32 for Z200 and 16 for Z500), resulting in a total biofilm surface area of $0.06,0.04,0.02 \mathrm{~m}^{2}$ for the batch containing Z50, Z200 and Z500 carriers, respectively. Other abiotic removal processes, such as volatilization, sorption of micropollutants on plastic carriers and glass wall, had been previously assessed and found negligible in MBBRs (Torresi et al., 2016).

Twenty-three micropollutants were spiked in all the beakers with an initial concentration of 1 $\mu \mathrm{g} \mathrm{L}^{-1}$ except for X-ray contrast media $\left(15 \mu \mathrm{g} \mathrm{L}^{-1}\right)$, as they are usually found at higher concentrations in effluent wastewater (Margot et al., 2015). A stock solution, containing micropollutants dissolved in methanol $\left(40 \mathrm{mg} \mathrm{L}^{-1}\right)$, was first spiked into empty glass beakers and the methanol was allowed to evaporate in the fumehood for approximately 1 hour. Subsequently, the solution was resuspended in filtered effluent for approximately 30 min to dissolve the spiked micropollutants. Biomass inactivation was achieved by: (i) addition of allylthiourea (ATU, $10 \mathrm{mg} \mathrm{L}{ }^{-1}$, Tran et al., 2009; Khunjar and Love, 2011) and nitrogen sparging (Hamon et al., 2014) to inhibit nitrfyng bacteria; and (ii) addition of sodium azide (0.5 $\mathrm{g} \mathrm{L}^{-1}$; Rattier et al., 2014) to inhibit the activity of heterotrophic bacteria.

The experiment duration was set to 4 hours. Homogenous aqueous samples were collected at regular intervals from the bulk phase in each beaker at $0,5,10,30,90$ and $240 \mathrm{~min}$. The batch experiments were performed at ambient temperature and initial $\mathrm{pH}$ was measured to be $7.5 \pm$ 0.5. Since only one spiking concentration was tested, results from sorption experiments were used to determine single point $K_{d}$ values. 


\subsection{Chemicals}

254 Twenty-three environmentally relevant micropollutants were selected for this study. The 255 targeted pharmaceuticals were grouped in six categories according to their use: (i) four beta256 blocker pharmaceuticals (atenolol, metoprolol, propranolol and sotalol); (ii) five X-ray contrast 257 media (diatrizoic acid, iohexol, iopamidol, iopromide, iomeprol); (iii) three sulfonamide 258 antibiotics (sulfadiazine, sulfamethizole and sulfamethoxazole), one metabolite (acetyl259 sulfadiazine) and one combination product (trimethoprim); (iv) three non-steroidal anti260 inflammatory pharmaceuticals (phenazone, diclofenac, ibuprofen); (v) three psycho-active 261 drugs (carbamazepine, venlafaxine and citalopram); (vi) three macrolide antibiotics 262 (erythromycin, clarithromycin and roxithromycin). Further information regarding chemical 263 structure and properties, CAS numbers and chemical suppliers can be found in Table S2-S3 264 and in Escolà Casas et al. (2015).

\subsection{Analytical methods}

267 Samples for micropollutant analysis were collected $(4 \mathrm{~mL})$ and analysed via direct injection 268 using internal standards (injected volume of $100 \mu \mathrm{L}$ ). Details regarding sample preparation, 269 internal standards, HPLC and mass spectrometry conditions, limits of detection and 270 quantification are shown in Escolà Casas et al. (2015). Biomass concentration on Z-carriers was 271 measured in two ways: (i) as attached biomass concentration (expressed as total attached 272 solids, TAS), calculated from the difference in weight of three dried carriers $\left(105^{\circ} \mathrm{C}\right.$ for $\left.>24 \mathrm{~h}\right)$ 273 before and after biofilm removal (using $2 \mathrm{M} \mathrm{H}_{2} \mathrm{SO}_{4}$ with subsequent brushing) (see also Escolà

274 Casas et al., 2015; Falås et al., 2013; Torresi et al., 2016); and (ii) by scraping and suspending 275 the biofilm in tap water and measuring total suspended solids (TSS) and volatile suspended 
solids (VSS) according to APHA standard methods (Clesceri, 1989). Biofilm properties such as biofilm dry density $\rho_{d}\left(\mathrm{~g} \mathrm{~cm}^{-3}\right)$, biomass density in wet biofilm $\rho\left(\mathrm{kg} \mathrm{m}^{-3}\right)$ and porosity $\varepsilon(\%)$ were calculated according to Tchobanoglous et al. (2003) and Hu et al. (2013) using measured biofilm properties (e.g., solids content), as detailed in the Supplementary Information (section S2). Porosity is defined as the fraction of the biofilm volume occupied only by water outside

281 the cells and not inside the cells (Hu et al., 2013). Furthermore, $\rho_{d}$ denotes the dry mass of biofilm per volume of dry biofilm (i.e., defines a true density) while $\rho$ denotes the dry mass of biomass per volume of wet biofilm (i.e., defines a concentration of biomass within the biofilm). Further discussion on the calculation methodology used and on the biofilm properties can be found in section $\mathrm{S} 2$.

\subsection{Statistical analysis and influence of chemical properties}

Pearson's and Spearman's correlations between $K_{d, e q}$ and chemical properties (expressed in logarithmic base) were assessed at different biofilm thicknesses. A significance level of 0.05 was used for all statistical tests in this study. The investigated physico-chemical properties include: the molecular volume $M V\left(\mathrm{~cm}^{3} \mathrm{~mol}^{-1}\right)$; the dissociation constant(s) $p K_{a}$; the number of rotable bonds $(n R B)$; the van der Waals area $\left(v d W A, \mathrm{~m}^{2} \mathrm{kmol}^{-1}\right)$ (Sathyamoorthy and Ramsburg, 2013); McGowan's approximation of the molecular volume $\left(V_{X}, \mathrm{~cm}^{3} \mathrm{~mol}^{-1}\right)$ (Droge and Goss, 2013a); and the topological polar surface area (TPSA, $\AA^{2}$ ) (Ertl et al., 2000). Chemical properties and $K_{d, e q}$ were log transformed (Vasudevan et al., 2009) with exception of

$296 n R B$ (Sathyamoorthy and Ramsburg, 2013) and molecular size descriptors $M V$ and $V_{X}$.

297 Chemical properties for each compound were retrieved using ACD/Labs predictions and the database Mol-inisticts (for $\log v d W A$ ) or calculated based on previously defined equations (for 
300 correlations and their significance were assessed using GraphPad Prism 5.0. Furthermore,

301 possible correlations between $f$ and the abovementioned properties were also investigated.

302 Significant differences between estimated $f$ values for each chemical at different biofilm thickness

303 were determined by examining the overlap between standard deviations of the estimate (Cumming

304 et al., 2007) 


\section{Results and discussion}

306

307

308

309

310

311

312

313

\subsection{Biofilm properties}

Measured and calculated values for a number of biofilm properties are reported in Table 1. Dry biofilm mass per surface area of carrier (gTAS m${ }^{-2}$, Table 1) increased with biofilm thickness, being approximately four times higher in Z500 compared to Z50. Biofilm thickness in Zcarriers was recently measured using optical coherence tomography (OCT), revealing good agreement between measured and nominal thickness based on carrier design (Piculell et al., 2016). Conversely, biofilm density in wet biofilm $\rho$ (section 1 in SI) in Z50 was up to 3-fold higher as compared to Z200 and Z500. This suggests a change in biofilm porosity as a function of biofilm thickness. Biofilm porosity $\varepsilon$ (Eq. S12), ranged from 75\% (Z50) to 93\% (Z500) (Table 1). An approximate porosity of $80 \%$ is commonly assumed in one-dimensional biofilm models (Wanner and Reichert, 1996; Brockmann et al., 2008) and similar values have been previously determined using modelling approximations (Zacarias et al., 2005; Zhang and Bishop, 1994b). The observed increasing $\varepsilon$ with biofilm thickness is in agreement with previous findings for Zcarrier biofilms (Piculell et al., 2016), although lower porosities (approximately of 10 and 30\% for Z50 and Z400) were estimated using OCT. Values of biofilm dry density $\rho_{d}$ (Table 1) for the three biofilms were comparable to that shown in literature (Hu et al., 2013), indicating a higher content of fixed solids in Z500.

\section{$<$ Table $1>$}

\subsection{Sorption coefficients in biofilms}

Sorption was considered significant when a relative concentration drop $\left(C_{L, 0}-C_{L, 4 h}\right) / C_{L, 0}$ higher than $10 \%$ was observed (Hörsing et al., 2011), thus accounting for analytical 
uncertainty. Profiles of aqueous concentration of the sorptive micropollutants measured during batch experiments are shown in Fig. 3 (duplicate measurement) and in Fig. S2.

330 Out of the 23 targeted compounds, sorption was significant only for eight micropollutants, 331 namely atenolol, metoprolol, propranolol, citalopram, venlafaxine, erythromycin, 332 clarithromycin and roxithromycin. The presence of chemicals not exhibiting sorption (e.g., 333 diclofenac and the targeted sulfonamides) suggests that biomass was successfully inhibited 334 during batch experiments, as most targeted compounds were significantly biodegraded in the 335 same MBBRs without biomass inhibition (Torresi et al. 2016). Interestingly, micropollutants 336 that were positively charged ( $>90 \%$ cationic fraction) at the experimental $\mathrm{pH}$ of 7.5 presented 337 significant sorption, with exception of sotalol and trimethoprim. Higher sorption potential of 338 positively charged compounds compared to negatively charged or neutral compounds was 339 previously observed for activated sludge biosolids (Stevens-Garmon et al., 2011; Polesel et al., $3402015)$ and soil (Franco and Trapp, 2008).

\subsubsection{Sorption coefficients $K_{d, e q}$ and comparison with activated sludge}

343 Sorption coefficients $K_{d, e q}$ in Z50, Z200 and Z500 biofilms were calculated for the above listed

344 cationic micropollutants (Table 2). $K_{d, e q}$ values were compared with previously found sorption 345 coefficients in activated sludge, for which the large majority of micropollutant sorption data 346 are available.

\section{< Table 2 >}

348 Values of $K_{d, e q}$ for atenolol at all the three biofilm thickness were up to 2-fold higher than 349 literature values for activated sludge (Radjenović et al., 2009; Stevens-Garmon et al., 2011), 350 while values in Z50 and Z200 were comparable with findings for secondary sludge (Hörsing et 351 al., 2011). As atenolol presents similar molecular properties to other beta-blockers (e.g., 
352

353

354

355

356

357

358

359

360

361

362

363

364

365

366

367

368

369

370

371

372

373

374

375

molecular weight, $p K_{a}$ ), the reasons behind this high sorption potential are unclear. As to metoprolol, $K_{d, e q}$ values in Z50, Z200 and Z500 were comparable to previously measured coefficients in activated sludge biomass (Maurer et al., 2007; Sathyamoorthy et al., 2013). Similarly to studies on sludge, propranolol exhibited the highest sorption potential of all selected beta-blockers (Maurer et al., 2007; Radjenović et al., 2009). Notably, a fourth targeted beta blocker sotalol did not show any significant sorption, in agreement with previous findings in activated sludge (Maurer et al., 2007; Sathyamoorthy et al., 2013).

Values of $K_{d, e q}$ for Z50 and Z200 were comparable with previous studies on conventional activated sludge and membrane bioreactor (MBR) sludge for clarithromycin (Abegglen et al., 2009; Göbel et al., 2005), erythromycin (Radjenović et al., 2009; Xue et al., 2010) and roxithromycin (Abegglen et al., 2009; Hörsing et al., 2011). On the contrary, $K_{d, e q}$ for Z500 differed by one order of magnitude from previously reported values. Nevertheless, $50-80 \%$ of dissolved clarithromycin and roxithromycin sorbed on MBR sludge (Abegglen et al., 2009), similarly to clarithromycin and erythromycin in this study $(\sim 80 \%)$. Furthermore, highly variable macrolide sorption was shown in soil and onto humic acids (Sibley and Pedersen, 2008; Uhrich et al., 2014), with estimated $K_{d, e q}$ values also higher than $8 \mathrm{~L} \mathrm{~g}^{-1}$ or $20 \mathrm{~L} \mathrm{~g}^{-1}$, respectively. Macrolides exhibited the highest $K_{d, e q}$ of all sorptive compounds in Z500 but not at lower biofilm thickness (Table 2). This might be related to the low porosity of the biofilms Z50 and Z200. According to Lipinksi's rule of five (Lipinski et al., 1997), macrolides are expected to poorly permeate across cell membranes and thus to move only in the intracellular space (depending on the porosity) due to their high molecular weight $\left(>500 \mathrm{~g} \mathrm{~mol}^{-1}\right)$. Furthermore, macrolides are mainly excreted in feces (Göbel et al., 2005) and due to protonation of the tertiary amino group, strong ionic interaction of macrolides with the negatively charged surface of the biomass could be expected. 
376 Few studies investigated the sorption of the antidepressant venlafaxine and the antiepileptic

377 citalopram. While sorption coefficients for Z50 and Z200 for both compounds are in agreement 378 with existing literature on activated sludge (Hörsing et al., 2011), higher values were found in 379 Z500 for citalopram.

380 In general, sorption coefficients of all the compounds at the three biofilm thicknesses were 381 comparable or higher than values observed with activated sludge biomass. Studies comparing 382 sorption onto MBR sludge and conventional activated sludge biomass (Joss et al., 2006; 383 Abegglen et al., 2009; Reif et al., 2011; Yi and Harper, 2007) revealed a sorption enhancement 384 in the former case. Increased sorption was associated to the smaller size of MBR sludge flocs 385 (assumed to be around $80-300 \mu \mathrm{m}$ in diameter), thus resulting in higher accessible surface area 386 (Tchobanoglous et al., 2003). In analogy with MBR sludge, it can be postulated that the high 387 accessible surface area in Z-carrier biofilms (related to the biofilm porous structure) may 388 explain the increased sorption capacity of most of the compounds compared to conventional 389 activated sludge biomass.

\subsubsection{Comparison between $K_{d, e q}$ and $K_{d, 4 h}$}

392 Sorption coefficients $K_{d, e q}$ were compared with $K_{d, 4 h}$ values for each chemical and relative 393 deviations $\Delta(\%)$ between these two coefficients were calculated at different biofilm 394 thicknesses (Table 2) to verify the equilibrium assumption within the experiment duration (4 395 hours). For most compounds, relative deviations for Z50 and Z200 were on average around $39610 \%$, with the exception of atenolol (>50\%). Conversely, $\Delta$ values in Z500 were for five 397 compounds higher than $30 \%$ (up to $80 \%$ for atenolol).

398 Overall, while the assumption of equilibrium reached within $4 \mathrm{~h}$ seems justified for Z50 and 399 Z200, diffusive mass transfer can significantly influence observations at higher biofilm 
400

401

402

403

404

405

406

407

408

409

410

411

412

413

thickness. Atenolol was the main exception, for which the 4-h equilibrium assumption seems not valid at any biofilm thickness. On the contrary, propranolol appeared to reach partitioning equilibrium within 4-h in Z50, Z200 and Z500, and similar considerations could be made for citalopram and venlafaxine. Therefore, to reduce uncertainties in sorption experiments, parameter estimation can benefit from calculating the asymptotic aqueous concentration value using e.g., simplified first-order decay equations (Eq. 4).

\subsubsection{Comparison between $K_{d, e q}$ and $K_{d, \text { sups }}$ and trends with biofilm thickness}

To assess the impact of biofilm porosity and mass transfer in pores on sorption coefficient estimation, the sorption coefficients $K_{d, e q}$ and $K_{d, s u s p}$ were compared (Table S4). In Fig. 2, this comparison is presented for two key chemicals (a: metoprolol, b: roxithromycin). For all micropollutants, neglecting the transport from bulk aqueous phase to biofilm pores resulted in an overestimation of sorption coefficients $\left(K_{d, s u s p}\right.$ always greater than $\left.K_{d, e q}\right)$. The relative deviation between $K_{d, s u s p}$ and $K_{d, e q}$ was on average $\leq 10 \%$ for most compounds and $30 \%$ for less sorptive compounds (metoprolol and venlafaxine).

We further observed that both $K_{d, e q}$ and $K_{d, s u s p}$ generally increased with increasing biofilm thickness (Fig. 2). Specifically, $K_{d, e q}$ values in Z500 were from 4-fold (most of the compounds) up to 30-fold higher (macrolides antibiotics) than in Z50 (Table 2). It should be highlighted that batch experiments were carried out at the same biomass concentration in the reactors $(0.8$ $\left.\mathrm{g} \mathrm{L}^{-1}\right)$. Consequently, the observed $K_{d, e q}$ increase with biofilm thickness likely derives from differences in biofilm composition and/or in its physical properties. Two possible explanations of this observation were proposed:

(i) Biomass composition, such as the relative fraction of autotrophic and heterotrophic bacteria and/or the content of extracellular polymeric substances (EPS), can influence sorption 
properties. EPS protein content was previously positively correlated with $K_{d}$ for aromatic chemicals in untreated and treated sewage sludge and colloids (Barret et al., 2010) and for the estrogen EE2 and trimethoprim in nitrifying and heterotrophic biomass (Khunjar and Love, 2011). Bassin et al., (2012) further observed higher concentration of proteins and polysaccharides (that mainly compose EPS) in heterotrophic MBBRs than in nitrifying MBBRs. Higher fractions of heterotrophic bacteria (determined using quantitative PCR of 16S rRNA) were measured in Z200 and Z500 compared to Z50 (Torresi et al., 2016), possibly justifying the increased sorption capacity in thicker biofilms (Z200, Z500). Further

432 investigation on the EPS content in the different biofilms is thus required to support this 433 hypothesis, given the key role of EPS in the sorption of neutral and ionizable organic 434 chemicals (Späth et al., 1998; Barret et al., 2010; Khunjar and Love, 2011).

435 (ii) Porosity can influence the available surface area inside the biofilm. Sorption has been 436 previously positively impacted by reduced particle size, i.e., greater surface area, in suspended 437 biomass (Khunjar and Love, 2011) and biomass floc suspension derived from MBRs (Yi and 438 Harper, 2007). Thicker biofilms, having lower biomass density and substantially higher 439 porosity than thin biofilms, could accordingly provide for higher available surface (and thus 440 more accessible sites) for solid-liquid partitioning.

441 Finally, $K_{d, e q}$ values were normalized to the highest value of $K_{d, e q}$ (i.e., for Z500, $K_{d, e q Z 500}$ ). The 442 obtained profiles followed two distinct trends as a function of biofilm thickness (Fig. 2c-d): (i) 443 beta-blockers and venlafaxine, exhibiting a logarithmic-like increase between Z50 and Z500; 444 and (ii) macrolides and citalopram, presenting significantly higher values for Z500, thus an 445 exponential-like increase of $K_{d, e q}$ with thickness. The question arises as to the influence of the 446 specific chemical properties of micropollutants on partitioning in biofilms, which was further 447 assessed using correlation analysis (see 4.5.2). 
$<$ Figure $2>$

\subsection{Modelling diffusion and sorption in biofilm}

451 Based on the considerations above, calculated $K_{d, e q}$ were used to calibrate the diffusionsorption model against experimental data for the estimation of the dimensionless effective diffusivity coefficient $f$ (the only parameter estimated with the model). Simulated aqueous concentrations (continuous lines, Fig. 3) predicted reasonably well the measured concentrations in bulk liquid (circles, Fig. 3) for most of the targeted compounds (i.e., for propranolol, clarithromycin, erythromycin, roxithromycin, citalopram, venlafaxine $\mathrm{R}^{2}>0.9$; Table S5). For atenolol, measured concentrations were less well predicted for Z50 and Z500 $\left(\mathrm{R}^{2}\right.$ equal to 0.8$)$

The simulated micropollutant concentrations in the bulk liquid and in the biofilm pores liquid (dashed lines, Fig. 3) should converge when partitioning equilibrium is reached. This 461 equilibrium condition was satisfied for most compounds in Z50 and Z200 within $4 \mathrm{~h}$ 462 experimental time, with an average $10 \%$ relative deviation between simulated concentrations in 463 bulk and in biofilm pores. For the thickest biofilm (Z500), however, model predictions for most of targeted chemicals suggested that equilibrium was not reached within $4 \mathrm{~h}(60 \%$ average discrepancy with the last measurement). It is likely that, due to the greater thickness,

466 increased time to diffuse in deeper biofilm and thus to achieve sorption equilibrium is required 467 in Z500. The exception was propranolol, for which equilibrium seemed to be reached in all the 468 three biofilms, thus supporting results (relative deviation between $K_{d, 4 h}$ and $K_{d, e q}$ ) presented in 469 Table 2. For macrolide antibiotics, this discrepancy was significant and simulation results 470 suggested a time for partitioning equilibrium of approximately 10 days-in good agreement 471 with equilibrium times (days, months and years) in other environmental matrices (Delle Site, 
2001). Furthermore, the large molecular volume and weight of macrolides (2- to 3 -fold higher than the other targeted compounds, Table S2), as well as their high sorption potential in Z500, suggest slower diffusive transport inside the biofilm, as previously observed for hydrophobic organic molecules in sediments and soil (Wu and Gschwend, 1986).

There is a large variability concerning the time to reach partitioning equilibrium for organic chemicals in biofilms (Alvarino et al., 2015; Headley et al., 1998; Shi et al., 2011; Wicke et al., 2008; Writer et al., 2011), with values ranging from, e.g., 4 to $80 \mathrm{~h}$ for biofilm of $0.1 \mathrm{~mm}$ thickness (Wicke et al., 2008). In conclusion, our observations conflict with the widely held assumption of significantly shorter period of time (i.e. minutes to 1-2 hours) necessary to reach equilibrium in activated sludge (e.g., Hörsing et al., 2011; Pomiès et al., 2013). This may be explained by differences in pore-scale (hydro)dynamic conditions in MBBRs and activated sludge reactors, resulting in more pronounced mass transfer limitation in MBBRs.

\section{$\langle$ Figure $3>$}

\subsection{Influence of biofilm and chemical properties on diffusion $(f)$ and partitioning $\left(K_{d, e q}\right)$}

\subsubsection{Estimation of $f$ and proposed empirical correlation}

Values of the dimensionless effective diffusivity coefficient $f$ estimated for the three biofilm thicknesses and the eight sorptive compounds are reported in Fig. 4. For most of the compounds, with the exception of roxithromycin, $f$ decreased with biofilm density and thus increased with biofilm thickness and porosity (with $f$ in Z500 significantly higher than in Z200 and Z50 for all the compounds, and $f$ in Z200 significantly higher than Z50 for six compounds). In thinner biofilms $(\leq 50 \mu \mathrm{m})$, the transport of micropollutants could thus be limited by the high biomass density and the reduced porosity. A number of regressions to estimate $f$ of solutes in biofilms as a function of biofilm density or porosity have been 
previously developed (Fan et al., 1990; Guimerà et al., 2016; Horn and Morgenroth, 2006;

497 Zhang and Bishop, 1994a), suggesting a negative correlation between $f$ and density. Selected 498 regression profiles (i.e., Guimerà et al., 2016; Horn and Morgenroth, 2006; Zhang and Bishop, 1994a; see Table S6) are reported in Fig. S3 for comparison with our $f$ estimations. In particular, Guimerá et al. (2016) observed strong mass transfer limitation $(f<0.1)$ for oxygen

501 in biofilm with density greater than $50 \mathrm{gVSS} \mathrm{L}^{-1}$, in close agreement with findings (specifically 502 for Z50) presented in this study.

504 In general, estimated $f$ were lower than values calculated from proposed regressions (Guimerà et al., 2016; Horn and Morgenroth, 2006; Zhang and Bishop, 1994a) (Fig. S3). While these regressions were identified for solutes with lower molecular weight $\left(<100 \mathrm{~g} \mathrm{~mol}^{-1}\right)$ and high solubility (e.g., $\mathrm{O}_{2}$, sodium chloride, sodium nitrate), lower values of $f(\sim 0.2)$ were reported for most organic solutes with larger molecular weight (e.g., sugars and fatty acids; Stewart, 2003, 509 1998).

510 Given the possible influence of chemical properties on micropollutant diffusivity, we evaluated 511 the relationship between $f$ and several physico-chemical descriptors (section 3.5). No specific 512 correlation was observed between $f$ and molecular volume and other descriptors (Fig. S4). We 513 observed a positive correlation only between $f$ and $\log K_{O W}$ of the targeted compounds (Fig. 514 S5), while negative dependence was reported in literature for organic compounds (Headley et 515 al., 1998; Wicke et al., 2007; Wu and Gschwend, 1986). Notably, in this study the correlation 516 was found for less hydrophobic $\left(0.1<\log K_{O W}<3.7\right)$ and positively charged compounds 517 (differently from previous studies), for which electrostatic interactions may also have 518 influenced transport and partitioning. Thus, an empirical correlation between $f$, biofilm density $519 \rho$ (as function of biofilm thickness) and $\log K_{O W}$ is proposed (Eq. 7): 
$520 f=\frac{1}{488 \cdot e^{-0.0072 L_{F}}} \ln \left(\frac{-12.7-\log K_{O W, \max }}{\log K_{o W}-\log K_{O W, \text { max }}}\right)$

521 where $L_{F}$ is the biofilm thickness $(\mu \mathrm{m})$ and $\log K_{O W, \max }$ is the asymptotic $\log K_{O W}$ 522 approximating the highest value for the compounds selected. Profiles of $f$ deriving from Eq. 7 523 were then depicted in Fig. 5, along with the estimated $f$ values for the three biofilm thickness 524 (symbols, see also Fig. 4). Further details on the formulation of Eq. 7 are given in the SI 525 (section S4). We note that the size of the available data set may not be sufficiently large to 526 validate the correlation, and additional experimental evidence (higher biofilm thickness, wider 527 range of $\left.\log K_{\text {OW}}\right)$ may be required for further confirmation.

\section{$\langle$ Figure $5>$}

\subsubsection{Predictors of micropollutant $K_{d, e q}$ in biofilms}

531 Correlation analyses were performed between $K_{d, e q}$ and a number of physico-chemical 532 micropollutant descriptors.

533 First, the octanol-water partitioning coefficient of the neutral species $\left(\log K_{O W}\right)$ and the species534 dependent octanol-water distribution coefficient $(\log D)$ were assessed, exhibiting insignificant 535 correlation with $K_{d, e q}(-0.27<$ Pearson's $\mathrm{r}<0.15$ for the three biofilms $)$. This finding confirms 536 the limited reliability of $\log K_{O W}$ and $\log D$ as sorption predictors for organic cations, as 537 previously shown in soil (Tolls, 2001; Franco and Trapp, 2008; Droge and Gross, 2013a).

538 Following this preliminary assessment, correlations with physico-chemical descriptors for 539 ionizable compounds (i.e., $\log p K_{a}, n r B, M V, \log T P S A, \log v d W A, V_{X}$ ) were investigated (Fig. 6 540 and S6). Correlations for biofilm Z50 was performed only considering six compounds $\left(K_{d, e q}=\right.$ 5410 for venlafaxine and roxithromycin). 
542 No significant correlations were found with the stereochemistry parameter $n R B$ and $\log p K_{a}$

543 (Fig.S6). While previous studies positively correlated the sorption of cationic compounds with

$544 p K_{a}\left(\mathrm{r}^{2}=0.5\right)$ (Franco and Trapp, 2008), the narrow range of $p K_{a}$ values covered in this study

545 prevented us from concluding on the significance of this indicator.

546 Interestingly, our analysis revealed a significant positive correlation only for Z500 between $547 \log K_{d, e q}$ and $\log T P S A, \log v d W A$, McGowan's $V_{X}$ (Fig. 6) and MV (Fig. S6a). The parameter 548 TPSA was previously identified as sorption predictor only for neutral and negatively charged 549 compounds, although with a negative correlation (Sathyamoorthy and Ramsburg, 2013). TPSA 550 reflects the polarity of the organic chemical by accounting for the oxygen and nitrogen atoms 551 as well as attached hydrogen atoms, and increased polar surface area has been associated to 552 reduced absorption and cell permeability of pharmaceuticals in humans (Palm et al., 1997; Ertl 553 et al., 2000). Hence, the significant correlation with $\log K_{d, e q}$ may suggest (at least for thicker 554 biofilm) a positive influence of polarity on the retention of cations in biofilm, possibly 555 resulting from the improved accessibility to deeper biofilm through transport in the 556 intracellular space.

558 On the other hand, the positive correlation of $\log K_{d, e q}$ with $\log v d W A, M V$ and $V_{X}$ still suggests 559 a contribution of hydrophobicity in sorption of positively charged compounds in Z500 biofilm. 560 This finding is in line with previously established regressions for the prediction of distribution 561 coefficients based on van der Waals volume (Kamlet et al., 1998) or $V_{X}$ (Abraham, 1993; 562 Abraham and Acree, 2010; Droge and Goss, 2013a,b,c) for neutral and ionized molecules. 563 Notably, McGowan's volume positively correlates with van der Waals volume (Zhao et al., 564 2003), which is itself correlated to $v d W A$. Hence, both $v d W A$ and $V_{X}$ provide an indication of 565 the influence of the molecular size in the cavity formation mechanism, through which solute 
molecules can distribute to an organic phase at the expenses of (i.e., by replacing) water

567 molecules (Mackay and Vasudevan, 2012).

568 Considering the relevance of the correlation between $\log K_{d, \text { eq }}$ and $V_{X}$ for Z500, an empirical

569 regression model (Eq. 8) was tested based on the equation previously proposed by Droge and

570 Goss $(2013 \mathrm{a}, \mathrm{c})$ for sorption prediction of organic cations to soil organic matter:

$571 \log K_{d, e q}=a \cdot V_{X} / 100+b \cdot N A_{q}+c$

572 where $K_{d, e q}$ is expressed in $\mathrm{L} \mathrm{kg}^{-1}$ and $N A_{i}$ indicates the number of hydrogen atoms bound to the 573 charged nitrogen moiety. The coefficients $a, b$ and $c$ were estimated by fitting Eq. 8 to 574 measured sorption coefficients. The comparison between predicted and measured $\log K_{d, e q}$ for 575 Z500 is shown in Fig. $6 \mathrm{~d}(a=0.35 ; b=0.45 ; c=1.48)$. The regression $\left(\mathrm{r}^{2}=0.58\right)$ could only 576 partly describe sorption of cationic micropollutants in Z500 biofilms, yielding rather good $K_{d, e q}$ 577 predictions (within factor 1.5 from measurements) for propranolol, clarithromycin, 578 erythromycin and roxythromycin. Potential improvement of sorption predictions may be 579 expected from the identification of correction factors for polar functional groups-an area 580 beyond the scope of this study due to the limited number of substances.

581 Overall, results from this assessment confirm the challenges in the identification of unique and 582 reliable sorption predictors for positively charged micropollutants in biofilm, as previously 583 recognized for other matrices (Kah and Brown, 2007; Franco and Trapp, 2008; Franco et al., 584 2009; Sathyamoorthy and Ramsburg, 2013; Droge and Goss, 2013a,c; Bittermann et al., 2016).

585 Nevertheless, it should be highlighted that in this study sorption was consistently observed 586 only for positively charged compounds, indicating that electrostatic interaction with negatively 587 charged biomass surfaces play a major role for sorption in biofilms. 


\section{Conclusions}

591 This study investigated the sorption and the diffusion of selected micropollutants in nitrifying

MBBR biofilms (thickness=50, 200, $500 \mu \mathrm{m}$ ) by means of targeted experiments and process modelling, leading to the following conclusions:

- Sorption in biofilm occurred only for eight positively charged micropollutants (i.e., three macrolides, three beta-blockers and two psycho-active pharmaceuticals) out of 23 targeted substances. Electrostatic interaction with the negatively charged biomass surfaces appears to play a major role in the sorption to biofilms.

- Values of the partitioning coefficient $K_{d, e q}$ increased with increasing biofilm thickness for most of the sorbed compounds, being related to the increasing biofilm porosity and thus the higher surface area accessible for sorption. Sorption equilibria were reached within the duration of sorption experiments $(4 \mathrm{~h})$ for a number of compounds in 50 and $200 \mu \mathrm{m}$ thick biofilms, but not in the thickest biofilm. Slower equilibrium in thick biofilms $(\geq 500 \mu \mathrm{m})$ is likely determined by the longer time required to diffuse in deeper biofilm. lower porosity) of thinner biofilms. density, while showing an increase with increasing porosity. This indicates that diffusive transport may be strongly limited by the higher biomass density (and the

- Significant positive correlations were observed between $\log K_{d \text {,eq }}$ and a limited number of chemical properties of micropollutants (topological polar surface area, van der Waals area and McGowan's volume) but not for all biofilm thicknesses, confirming the challenges in the prediction of sorption in biofilms and other matrices for positively 
$614 \quad$ charged compounds.

615

616 Acknowledgments

617 This research was also supported by MERMAID, ITN funded by the People Programme (Marie

618 Skłodowska-Curie Actions) of the EU FP7/2007-2013/ under REA grant agreement $\mathrm{n}^{\circ}$

619 607492'. F. Polesel and S. Trapp gratefully acknowledge the project LRI-ECO32 RABIT, 620 funded under the CEFIC Long Range Research Initiative. 


\section{References}

Abegglen, C., Joss, A., McArdell, C.S., Fink, G., Schlüsener, M.P., Ternes, T.A., Siegrist, H., 2009. The fate of selected micropollutants in a single-house MBR. Water Res. 43, 203646.

Abraham, M.H., McGowan, J.C., 1987. The use of characteristic volumes to measure cavity terms in reversed phase liquid chromatography. Chromatogr. 23, 243-246.

Abraham, M.H., 1993. Scales of solute hydrogen-bonding: Their construction and application to physicochemical and biochemical processes. Chem. Soc. Rev. 22, 73-83.

Abraham, M.H., Acree Jr., W.E., 2010. Equations for the transfer of neutral molecules and ionic species from water to organic phases. J. Org. Chem. 75, 1006-1015

Alvarino, T., Suarez, S., Katsou, E., Vazquez-Padin, J., Lema, J.M., Omil, F., 2015. Removal of PPCPs from the sludge supernatant in a one stage nitritation/anammox process. Water Res. 68, 701-709.

Andersen, H.R., Hansen, M., Kjølholt, J., Stuer-Lauridsen, F., Ternes, T., Halling- Sørensen, B., 2005. Assessment of the importance of sorption for steroid estrogens removal during activated sludge treatment. Chemosphere 61, 139-146.

Barret, M., Carrère, H., Latrille, E., Wisniewski, C., Patureau, D., 2010. Micropollutant and sludge characterization for modeling sorption equilibria. Environ. Sci. Technol. 44, 11001106.

Barret, M., Carrere, H., Patau, M., Patureau, D., 2011. Kinetics and reversibility of micropollutant sorption in sludge. J. Environ. Monit. 13, 2770-2774.

Bassin, J.P., Kleerebezem, R., Rosado, A.S., van Loosdrecht, M.C.M., Dezotti, M., 2012. Effect of different operational conditions on biofilm development, nitrification, and nitrifying microbial population in moving-bed biofilm reactors. Environ. Sci. Technol. 46, 
$1546-1555$.

646 Beyenal, H., Lewandowski, Z., 2005. Modeling mass transport and microbial activity in stratified biofilms. Chem. Eng. Sci. 60, 4337-4348.

Berthod, L., Whitley, D.C., Roberts, G., Sharpe, A., Greenwood, R., Mills, G.A., 2017. Quantitative structure-property relationships for predicting sorption of pharmaceuticals to sewage sludge during waste water treatment processes. Sci. Total Environ. 579, 15121520.

Bittermann, K., Spycher, S., Goss, K.U., 2016. Comparison of different models predicting the phospholipid-membrane water partition coefficients of charged compounds. Chemosphere $144,382-391$.

Brockmann, D., Rosenwinkel, K.H., Morgenroth, E., 2008. Practical identifiability of biokinetic parameters of a model describing two-step nitrification in biofilms. Biotechnol.

Clesceri, L.S., 1989. Standard methods for the examination of water and wastewater. American Bioeng. 101, 497-514. Public Health Association.

Converti, A., Del Borghi, M., Zilli, M., 1997. Evaluation of phenol diffusivity through Pseudomonas putida biofilms: Application to the study of mass velocity distribution in a biofilter. Bioprocess Eng. 16, 105-114.

Cumming, G., Fidler, F., Vaux, D.L., 2007. Error bars in experimental biology. J. Cell Biol. $177,7-11$.

Delle Site, A., 2001. Factors affecting sorption of organic compounds in natural sorbent/water systems and sorption coefficients for selected pollutants. A review. J. Phys. Chem. Ref. Data 30, 187-439. 
matter: Influence of amine type and nonionic interactions at two different pHs. Environ. Sci. Technol. 47, 798-806.

Droge, S.T.J., Goss, K.U., 2013b. Sorption of organic cations to phyllosilicate clay minerals: CEC normalization, salt dependency, and the role of electrostatic and hydrophobic effects. Environ. Sci. Technol. 47, 14224-14232.

Droge, S.T.J., Goss, K.U., 2013c. Development and evaluation of a new sorption model for organic cations in soil: Contributions from organic matter and clay minerals. Environ. Sci. Technol. 47, 14233-14241.

Ertl, P., Rohe, B., Selzer, P., 2000. Fast calculation of molecular polar surface area as sum of fragment-based contributions and its application to the prediction of drug transport properties. J. Med. Chem. 43, 3714-3717.

680 Escolà Casas, M.E., Chhetri, R.K., Ooi, G., Hansen, K.M.S., Litty, K., Christensson, M., hospital wastewater by staged Moving Bed Biofilm Reactors (MBBR). Water Res. 83,

Falås, P., Longrée, P., la Cour Jansen, J., Siegrist, H., Hollender, J., Joss, A, 2013. $293-302$. Micropollutant removal by attached and suspended growth in a hybrid biofilm-activated sludge process. Water Res. 47, 4498-4506.

Fan, L.S., Leyva-Ramos, R., Wisecarver, K.D., Zehner, B.J., 1990. Diffusion of phenol through a biofilm grown on activated carbon particles in a draft-tube three-phase fluidized-bed bioreactor. Biotechnol. Bioeng. 35, 279-286.

690 Fernandez-Fontaina, E., Omil, F., Lema, J.M., Carballa, M., 2012. Influence of nitrifying 691 conditions on the biodegradation and sorption of emerging micropollutants. Water Res. $69246,5434-5444$. 
693 Franco, A., Fu, W., Trapp, S., 2009. Influence of soil pH on the sorption of ionizable 694 chemicals: modeling advances. Environ. Toxicol. Chem. 28, 458-464.

695 Franco, A., Struijs, J., Gouin, T., Price, O.R., 2013. Evolution of the sewage treatment plant 696 model SimpleTreat: Applicability domain and data requirements. Integr. Environ. Assess.

698 Franco, A., Trapp, S., 2008. Estimation of the soil-water partition coefficient normalized to 699 organic carbon for ionizable organic chemicals. Environ. Toxicol. Chem. 27, 1995-2004.

Göbel, A., Thomsen, A., McArdell, C.S., Joss, A., Giger, W., 2005. Occurrence and sorption 703

Hayduk, W., Laudie, H., 1974. Prediction of diffusion coefficients for nonelectrolytes in dilute behavior of sulfonamides, macrolides, and trimethoprim in activated sludge treatment. Environ. Sci. Technol. 39, 3981-3989.

Guimerà, X., Dorado, A.D., Bonsfills, A., Gabriel, G., Gabriel, D., Gamisans, X., 2016. Dynamic characterization of external and internal mass transport in heterotrophic biofilms from microsensors measurements. Water Res. 102, 551-560.

Hamon, P., Villain, M., Marrot, B., 2014. Determination of sorption properties of micropollutants: What is the most suitable activated sludge inhibition technique to preserve the biomass structure? Chem. Eng. J. 242, 260-268.

711 Headley, J. V., Gandrass, J., Kuballa, J., Peru, K.M., Gong, Y., 1998. Rates of sorption and 712 partitioning of contaminants in river biofilm. Environ. Sci. Technol. 32, 3968-3973.

713 Holden, P.A., Hunt, J.R., Firestone, M.K., 1997. Toluene diffusion and reaction in unsaturated 714 Pseudomonas putida biofilms. Biotechnol. Bioeng. 56, 656-670.

715 Horn, H., Morgenroth, E., 2006. Transport of oxygen, sodium chloride, and sodium nitrate in 716 biofilms. Chem. Eng. Sci. 61, 1347-1356. 
717 Hörsing, M., Ledin, A., Grabic, R., Fick, J., Tysklind, M., Jansen, J. la C., Andersen, H.R.,

718 2011. Determination of sorption of seventy-five pharmaceuticals in sewage sludge. Water $719 \quad$ Res. 45, 4470-4482.

720 Hu, M., Zhang, T.C., Stansbury, J., Neal, J., Garboczi, E.J., 2013. Determination of porosity 721 and thickness of biofilm attached on irregular-shaped media. J. Environ. Eng. 139, 923722931.

723 Hyland, K.C., Dickenson, E.R. V, Drewes, J.E., Higgins, C.P., 2012. Sorption of ionized and neutral emerging trace organic compounds onto activated sludge from different wastewater treatment configurations. Water Res. 46, 1958-1968.

Joss, A., Andersen, H., Ternes, T., Richle, P.R., Siegrist, H., 2004. Removal of estrogens in municipal wastewater treatment under aerobic and anaerobic conditions: consequences for plant optimization. Environ. Sci. Technol. 38, 3047-3055.

Joss, A., Zabczynski, S., Göbel, A., Hoffmann, B., Löffler, D., McArdell, C.S., Ternes, T. a., Thomsen, A., Siegrist, H., 2006. Biological degradation of pharmaceuticals in municipal

Kah, M., Brown, C.D., 2007. Prediction of the adsorption of lonizable pesticides in soils. J. Agric. Food Chem. 55, 2312-2322.

Kamlet, M.J., Doherty, R.M., Abraham, M.H., Marcus, Y., Taft, R.W., 1988. Linear solvation energy relationships. 46. An improved equation for correlation and prediction of octanol/water partition coefficients of organic nonelectrolytes (including strong hydrogen bond donor solutes). J. Phys. Chem. 92, 5244-5255.

Khunjar, W.O., Love, N.G., 2011. Sorption of carbamazepine, 17 $\alpha$-ethinylestradiol, iopromide 739 and trimethoprim to biomass involves interactions with exocellular polymeric substances. Chemosphere 82, 917-922. 
741 Lipinski, C.A., Lombardo, F., Dominy, B.W., Feeney, P.J., 1997. Experimental and 742 Computational Approaches to Estimate Solubility and Permeability in Drug Discovery 743 and Develop ment Settings. Adv. Drug Deliv. Rev. 23, 3-25.

744 Margot, J., Rossi, L., Barry, D.A., Holliger, C., 2015. A review of the fate of micropollutants 745 in wastewater treatment plants. Wiley Interdiscip. Rev. Water 2, 457-487.

746 Maurer, M., Escher, B.I., Richle, P., Schaffner, C., Alder, a C., 2007. Elimination of beta747 blockers in sewage treatment plants. Water Res. 41, 1614-1622.

748 Mackay, A.A., Vasudevan, D., 2012. Polyfunctional ionogenic compound sorption: Challenges 749 and new approaches to advance predictive models. Environ. Sci. Technol. 46, 9209-9223.

750 Ort, C., Gujer, W., 2008. Sorption and high dynamics of micropollutants in sewers. Water Sci. $751 \quad$ Technol. 57, 1791-1797.

752 Palm, K., Stenberg, P., Luthman, K., Artursson, P., 1997. Polar molecular surface properties 753 predict the intestinal absorption of drugs in humans. Pharm. Res. 14, 568-571.

754 Piculell, M., Suarez, C., Li, C., Christensson, M., Persson, F., Wagner, M., Hermansson, M., 755 Jonsson, K., Welander, T., 2016. The inhibitory effects of reject water on nitrifying 756 populations grown at different biofilm thickness. Water Res. 104, 292-302.

757

758

759

760

761

762

763

764

Plósz, B.G., Langford, K.H., Thomas, K. V, 2012. An activated sludge modeling framework for xenobiotic trace chemicals (ASM-X): assessment of diclofenac and carbamazepine. Biotechnol. Bioeng. 109, 2757-2769.

Plósz, B.G.Y., Leknes, H., Thomas, K. V, 2010. Impacts of competitive inhibition, parent compound formation and partitioning behavior on the removal of antibiotics in municipal wastewater treatment. Environ. Sci. Technol. 44, 734-742.

Polesel, F., Lehnberg, K., Dott, W., Trapp, S., Thomas, K. V, Plósz, B.G., 2015. Factors influencing sorption of ciprofloxacin onto activated sludge: Experimental assessment and 
modelling implications. Chemosphere 119, 105-111.

Pomiès, M., Choubert, J.-M., Wisniewski, C., Coquery, M., 2013. Modelling of micropollutant removal in biological wastewater treatments: a review. Sci. Total Environ. 443, 733-748.

Radjenović, J., Petrović, M., Barceló, D., 2009. Fate and distribution of pharmaceuticals in wastewater and sewage sludge of the conventional activated sludge (CAS) and advanced membrane bioreactor (MBR) treatment. Water Res. 43, 831-841.

Rattier, M., Reungoat, J., Keller, J., Gernjak, W., 2014. ScienceDirect Removal of micropollutants during tertiary wastewater treatment by biofiltration: Role of nitrifiers and removal mechanisms. Water Res. 54, 89-99.

Reichert, P., 1994. Aquasim - a tool for simulation and data-analysis of aquatic systems. Water Sci. Technol. 30, 21-30.

Reif, R., Besancon, A., Le Corre, K., Jefferson, B., Lema, J.M., Omil, F., 2011. Comparison of PPCPs removal on a parallel-operated MBR and AS system and evaluation of effluent post-treatment on vertical flow reed beds. Water Sci. Technol. 63, 2411-2417.

Sathyamoorthy, S., Ramsburg, C.A., 2013. Assessment of quantitative structural property relationships for prediction of pharmaceutical sorption during biological wastewater treatment. Chemosphere 92, 639-646.

Shi, Y.J., Wang, X.H., Qi, Z., Diao, M.H., Gao, M.M., Xing, S.F., Wang, S.G., Zhao, X.C., 2011. Sorption and biodegradation of tetracycline by nitrifying granules and the toxicity of tetracycline on granules. J. Hazard. Mater. 191, 103-109.

Sibley, S.D., Pedersen, J.A., 2008. Interaction of the macrolide antimicrobial clarithromycin with dissolved humic acid. Environ. Sci. Technol. 42, 422-428.

Späth, R., Flemming, H.C., Wuertz, S. (1998). Sorption properties of biofilms. Water Sci. Technol. 37, 207-210. 
Stevens-Garmon, J., Drewes, J.E., Khan, S.J., McDonald, J.A., Dickenson, E.R. V, 2011. Sorption of emerging trace organic compounds onto wastewater sludge solids. Water Res. $45,3417-3426$.

Stewart, P.S., 2003. Diffusion in Biofilms: why is diffusion an important process. J. Bacteriol. $185,1485-1491$.

Stewart, P.S., 1998. A review of experimental measurements of effective diffusive permeabilities and effective diffusion coefficients in biofilms. Biotechnol. Bioeng. 59, $261-272$.

Tchobanoglous G., Burton F., Stensel H., Wastewater Engineering: Treatment and Reuse, $4^{\text {th }}$ ed., Metcalf and Eddy, Inc., McGraw-Hill Company, New York, 2003.

Ternes, T.A., Herrmann, N., Bonerz, M., Knacker, T., Siegrist, H., Joss, A., 2004. A rapid method to measure the solid-water distribution coefficient $\left(\mathrm{K}_{\mathrm{d}}\right)$ for pharmaceuticals and musk fragrances in sewage sludge. Water Res. 38, 4075-4084.

Tolls, J. (2001). Sorption of veterinary pharmaceuticals in soils: A review. Environ. Sci. Technol. 35, 3397-3406

Torresi, E., Fowler, S.J., Polesel, F., Bester, K., Andersen, H.R., Smets, B.F., Plósz, B.G., Christensson, M., 2016. Biofilm Thickness Influences Biodiversity in Nitrifying MBBRs-Implications on Micropollutant Removal. Environ. Sci. Technol., 50 (17), 9279-9288.

Tran, N.H., Urase, T., Kusakabe, O., 2009. The characteristics of enriched nitrifier culture in the degradation of selected pharmaceutically active compounds. J. Hazard. Mater. 171, $1051-1057$.

Trapp, S., Matthies, M., 1998. Transport and Transformation of Compounds in Soil, in: Chemodynamics and Environmental Modeling. Springer-Verlag, Berlin, Germany. 
813 Uhrich, S.R.W., Navarro, D.A., Zimmerman, L., Aga, D.S., 2014. Assessing antibiotic sorption

814 in soil: A literature review and new case studies on sulfonamides and macrolides. Chem.

$815 \quad$ Cent. J. 8, 1-12.

816 Vasiliadou, I.A., Molina, R., Martínez, F., Melero, J. a, 2014. Experimental and modeling 817 study on removal of pharmaceutically active compounds in rotating biological contactors. 818 J. Hazard. Mater. 274, 473-482.

819 Wanner, O., Reichert, P., 1996. Mathematical modeling of mixed-culture biofilms. Biotechnol. $820 \quad$ Bioeng. 49, 172-184.

821 Wicke, D., Böckelmann, U., Reemtsma, T., 2007. Experimental and modeling approach to 822 study sorption of dissolved hydrophobic organic contaminants to microbial biofilms. $823 \quad$ Water Res. 41, 2202-2210.

824 Wicke, D., Böckelmann, U., Reemtsma, T., 2008. Environmental influences on the partitioning 825 and diffusion of hydrophobic organic contaminants in microbial biofilms. Environ. Sci. 826 Technol. 42, 1990-1996.

827 Writer, J.H., Ryan, J.N., Barber, L.B., 2011. Role of biofilms in sorptive removal of steroidal 828 hormones and 4-nonylphenol compounds from streams. Environ. Sci. Technol. 45, 7275$829 \quad 7283$.

830 Wu, S.C., Gschwend, P.M., 1986. Sorption kinetics of hydrophobic organic compounds to 831 natural sediments and soils. Environ. Sci. Technol. 20, 717-725.

832 Wunder, D.B., Bosscher, V.A., Cok, R.C., Hozalski, R.M., 2011. Sorption of antibiotics to 833 biofilm. Water Res. 45, 2270-2280.

834 Xue, W., Wu, C., Xiao, K., Huang, X., Zhou, H., Tsuno, H., Tanaka, H., 2010. Elimination and 835 fate of selected micro-organic pollutants in a full-scale anaerobic/anoxic/aerobic process 836 combined with membrane bioreactor for municipal wastewater reclamation. Water Res. 
44, 5999-6010.

838 Yi, T., Harper, W.F., 2007. The effect of biomass characteristics on the partitioning and 839 sorption hysteresis of 17alpha-ethinylestradiol. Water Res. 41, 1543-1553.

840 Zacarias, G.D., Ferreira, C.P., Velasco-Hernandez, J.X., 2005. Porosity and tortuosity relations 841 as revealed by a mathematical model of biofilm structure. J. Theor. Biol. 233, 245-251.

842 Zhang, S.F., Splendiani, A., Freitas dos Santos, L.M., Livingston, A.G., 1998. Determination 843 of pollutant diffusion coefficients in naturally formed biofilms using a single tube 844 extractive membrane bioreactor. Biotechnol. Bioeng. 59, 80-89.

845 Zhang, T.C., Bishop, P.L., 1994a. Evaluation of turtuosity factors and effective diffusivities in 846 biofilms. Water Res. 28, 2279-2287.

847 Zhang, T.C., Bishop, P.L., 1994c. Density, porosity, and pore structure of biofilms. Water Res. $848 \quad 28,2267-2277$.

849 Zhao, Y.H., Abraham, M.H., Zissimos, A.M., 2003. Determination of McGowan volumes for $850 \quad$ ions and correlation with van der Waals volumes. J. Chem. Inf. Comput. Sci. 43, 1848$851 \quad 1854$. 
Table 1. Biofilm characteristics and input parameters used in the sorption and diffusion model in this study. The parameter $\rho_{d}$ denotes the dry mass of biofilm per volume of dry biofilm (defining a true density), while $\rho$ denotes the dry mass of (microbial) biomass per volume of wet biofilm (defining the concentration of biomass within the biofilm). TAS defines total attached solids.

\begin{tabular}{ccccc}
\hline Parameter & Z50 & Z200 & Z500 & Reference \\
& & & & \\
\hline Dry biofilm mass per carrier $\left(\mathrm{gTAS} \mathrm{m}^{-2}\right)$ & $2.6 \pm 0.2$ & $4.0 \pm 0.3$ & $8.0 \pm 0.6$ & Measured \\
Biofilm dry density $\rho_{d}\left(\mathrm{~g} \mathrm{~cm}^{-3}\right)$ & $1.05 \pm 0.09$ & $1.05 \pm 0.07$ & $1.17 \pm 0.05$ & Calculated \\
Biomass density in wet biofilm $\rho\left(\mathrm{kg} \mathrm{m}^{-3}\right)$ & $51.9 \pm 2.6$ & $20.0 \pm 1.3$ & $16.0 \pm 0.8$ & Calculated \\
Porosity $\varepsilon(\%)$ & $75 \pm 4$ & $91 \pm 6$ & $93 \pm 7$ & Calculated \\
Biomass concentration in batch reactor & & & & \\
$\left(\right.$ gTAS L $\left.^{-1}\right)$ & $0.80 \pm 0.07$ & $0.78 \pm 0.06$ & $0.78 \pm 0.03$ & Measured \\
\end{tabular}


Table 2. Sorption coefficients calculated using the asymptotic equilibrium concentration $\left(K_{d, e q}\right.$, $\mathrm{L} \mathrm{g}^{-1}$; mean and standard deviation are given) and the last measured aqueous concentration $(\mathrm{t}=4 \mathrm{~h})$ during batch experiments $\left(K_{d, 4 h}, \mathrm{~L} \mathrm{~g}^{-1}\right)$ for eight of the 23 spiked chemical compounds. The parameter $\Delta(\%)$ defines the relative deviation between the two $K_{d}$ values, providing also an indication of the deviation from partitioning equilibrium. Literature $K_{d}$ values comprise measured partition coefficients in conventional activated sludge and membrane bioreactor (MBR) sludge.

\begin{tabular}{|c|c|c|c|c|c|c|c|c|c|c|}
\hline & \multicolumn{3}{|c|}{$\mathbf{Z 5 0}$} & \multicolumn{3}{|c|}{$\mathbf{Z 2 0 0}$} & \multicolumn{3}{|c|}{$\mathrm{Z500}$} & \multirow[b]{2}{*}{$\begin{array}{c}\text { Literature } K_{d} \\
\left(\mathbf{L ~ g}^{-1}\right)\end{array}$} \\
\hline & $\begin{array}{c}K_{d, e q} \\
\left(\mathbf{L ~ g ~}^{-1}\right)\end{array}$ & $\begin{array}{c}K_{d, 4 h} \\
\left(\mathbf{L ~ g ~}^{-1}\right)\end{array}$ & $\begin{array}{c}\Delta \\
(\%)\end{array}$ & $\begin{array}{c}K_{d, e q} \\
\left(\mathbf{L ~ g ~}^{-1}\right)\end{array}$ & $\begin{array}{c}K_{d, 4 h} \\
\left(\mathbf{L ~ g}^{-1}\right)\end{array}$ & $\begin{array}{c}\Delta \\
(\%)\end{array}$ & $\begin{array}{c}K_{d, e q} \\
\left(\mathbf{L ~ g ~}^{-1}\right)\end{array}$ & $\begin{array}{c}K_{d, 4 h} \\
\left(\mathbf{L ~ g ~}^{-1}\right)\end{array}$ & $\begin{array}{c}\Delta \\
(\%)\end{array}$ & \\
\hline Atenolol & $1.12 \pm 2.21$ & 0.26 & 77 & $1.12 \pm 0.34$ & 0.68 & 38 & $4.84 \pm 0.73$ & 0.95 & 80 & $(0.006)^{1}-1.9^{2}$ \\
\hline Metoprolol & $0.08 \pm 0.01$ & 0.08 & 3 & $0.19 \pm 0.06$ & 0.16 & 15 & $0.28 \pm 0.02$ & 0.15 & 44 & $<0.01^{3}-0.23^{4}$ \\
\hline Propranolol & $0.50 \pm 0.04$ & 0.54 & -9 & $1.71 \pm 0.03$ & 1.67 & 1 & $1.95 \pm 0.06$ & 1.92 & -1 & $0.2^{1}-0.32^{3}$ \\
\hline Clarithromycin & $0.42 \pm 0.11$ & 0.34 & 20 & $0.41 \pm 0.02$ & 0.39 & 4 & $11.19 \pm 0.20$ & 5.63 & 48 & $0.26^{5}-1.2^{6}$ \\
\hline Erythromycin & $0.33 \pm 0.07$ & 0.34 & -3 & $0.20 \pm 0.01$ & 0.20 & -4 & $11.28 \pm 2.10$ & 6.13 & 43 & $0.31^{1}-1.0^{7}$ \\
\hline Roxithromycin & 0.00 & 0.00 & l & $0.86 \pm 0.13$ & 1.05 & -24 & $11.10 \pm 0.30$ & 3.92 & 64 & $<0.1^{8}-0.5^{6}$ \\
\hline Citalopram & $0.47 \pm 0.08$ & 0.46 & 1 & $0.67 \pm 0.08$ & 0.61 & 8 & $2.52 \pm 0.15$ & 2.06 & 16 & $0.54^{2}$ \\
\hline Venlafaxine & 0.00 & 0.00 & 1 & $0.12 \pm 0.05$ & 0.09 & 25 & $0.14 \pm 0.06$ & 0.12 & 16 & $<0.1^{2}$ \\
\hline
\end{tabular}

${ }^{1}$ (Radjenović et al., 2009) for atenolol the lowest value was in MBR sludge; ${ }^{2}$ (Hörsing et al., 2011) for atenolol in activated sludge; ${ }^{3}$ (Maurer et al., 2007); ${ }^{4}$ (Sathyamoorthy et al., 2013); ${ }^{5}$ (Göbel et al., 2005); ${ }^{6}$ (Abegglen et al., 2009) in MBR; ${ }^{7}$ (Xue et al., 2010) in conventional activated sludge and MBR sludge; ${ }^{8}$ (Fernandez-Fontaina et al., 2012). 


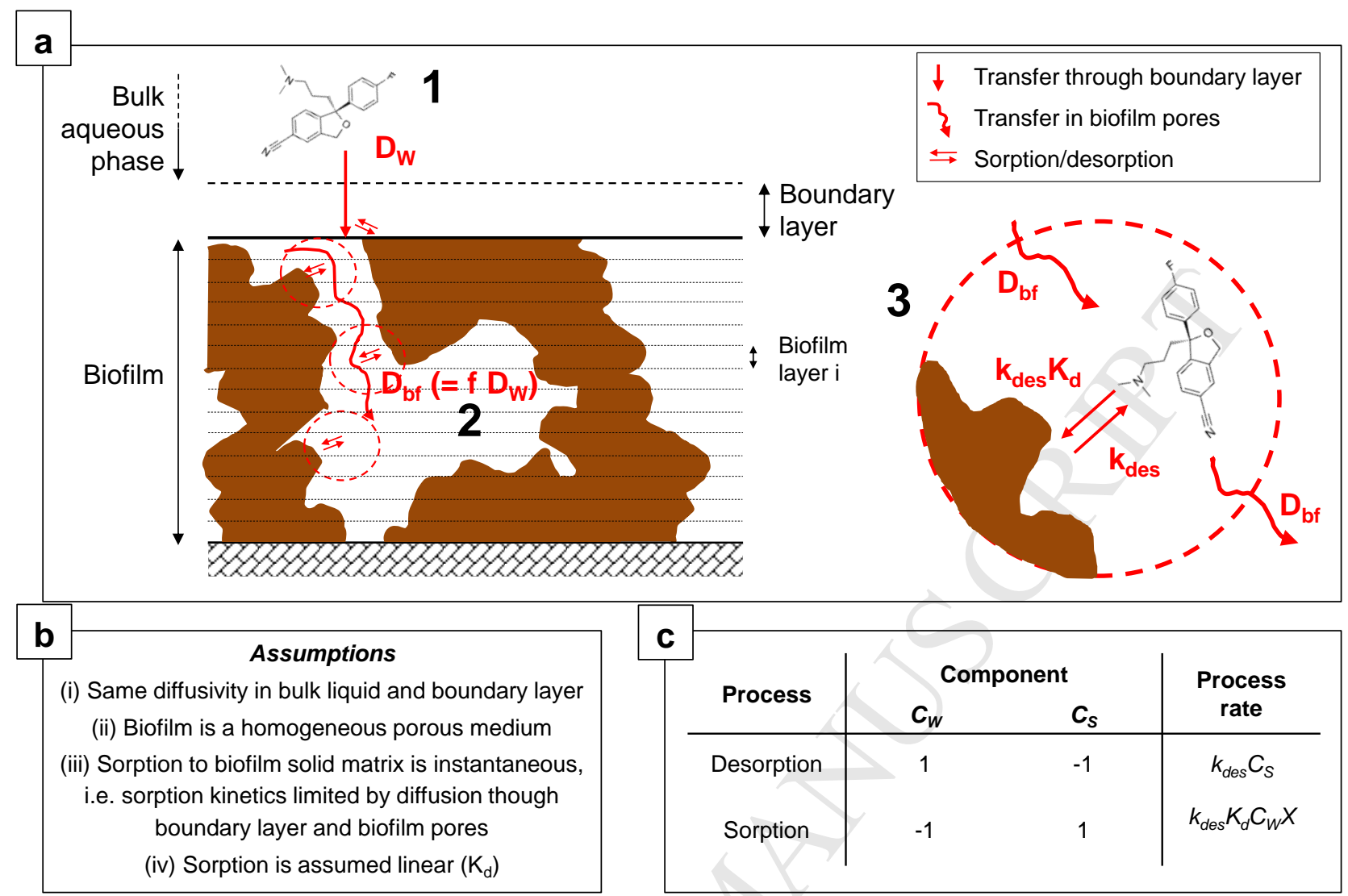

Figure 1. Conceptual model for diffusion and sorption of micropollutants into biofilms, including (a) a graphical description of the biofilm as porous medium, with discretization in 20 finite completely mixed layers, and of the consecutive steps required for partitioning onto biofilm solids (processes 1-3, see text); (b) the assumptions considered in the model; and (c) the process matrix describing sorption and desorption kinetics. 

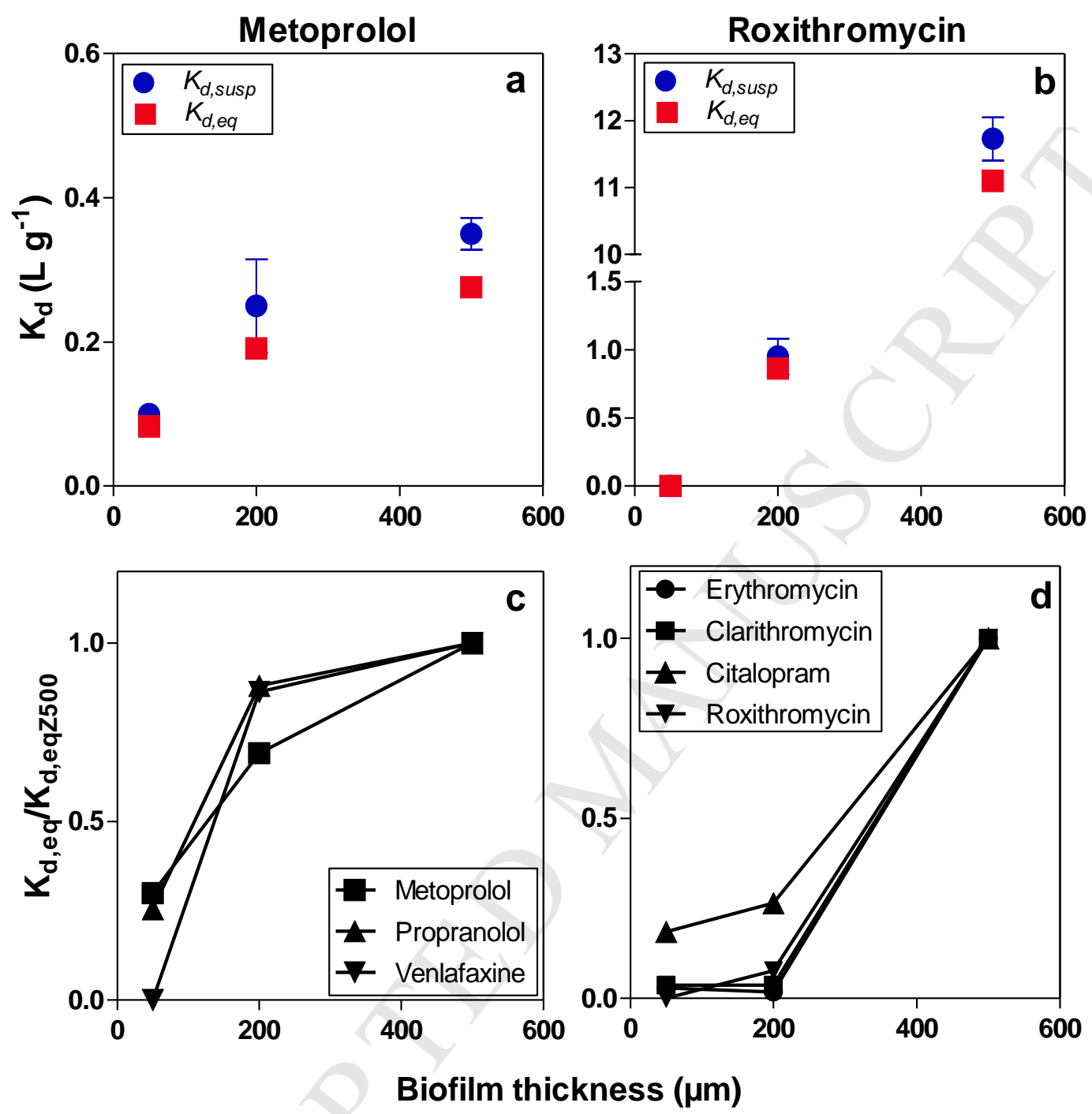

Figure 2. Values of the sorption coefficient calculated by accounting for and by neglecting biofilm porosity, $K_{d, s u s p}$ and $K_{d, e q}$, respectively for metoprolol (a) and roxithromycin (b). Different profiles of $K_{d, e q}$ normalized to $K_{d, e q, Z 500}$ (i.e., for biofilm Z500) as a function of biofilm thickness are also shown for the sorptive micropollutants (c and d). 


\begin{tabular}{|cccc|}
\hline$\frown$ & $Z 50$ & $\cdots$ & $C_{L}$ sim. in biofilm Z50 \\
- & $Z 200$ & $\cdots$ & $C_{L}$ sim. in biofilm Z200 \\
$\bigcirc$ & $Z 500$ & $\cdots$ & $C_{L}$ sim. in biofilm Z500 \\
\hline
\end{tabular}
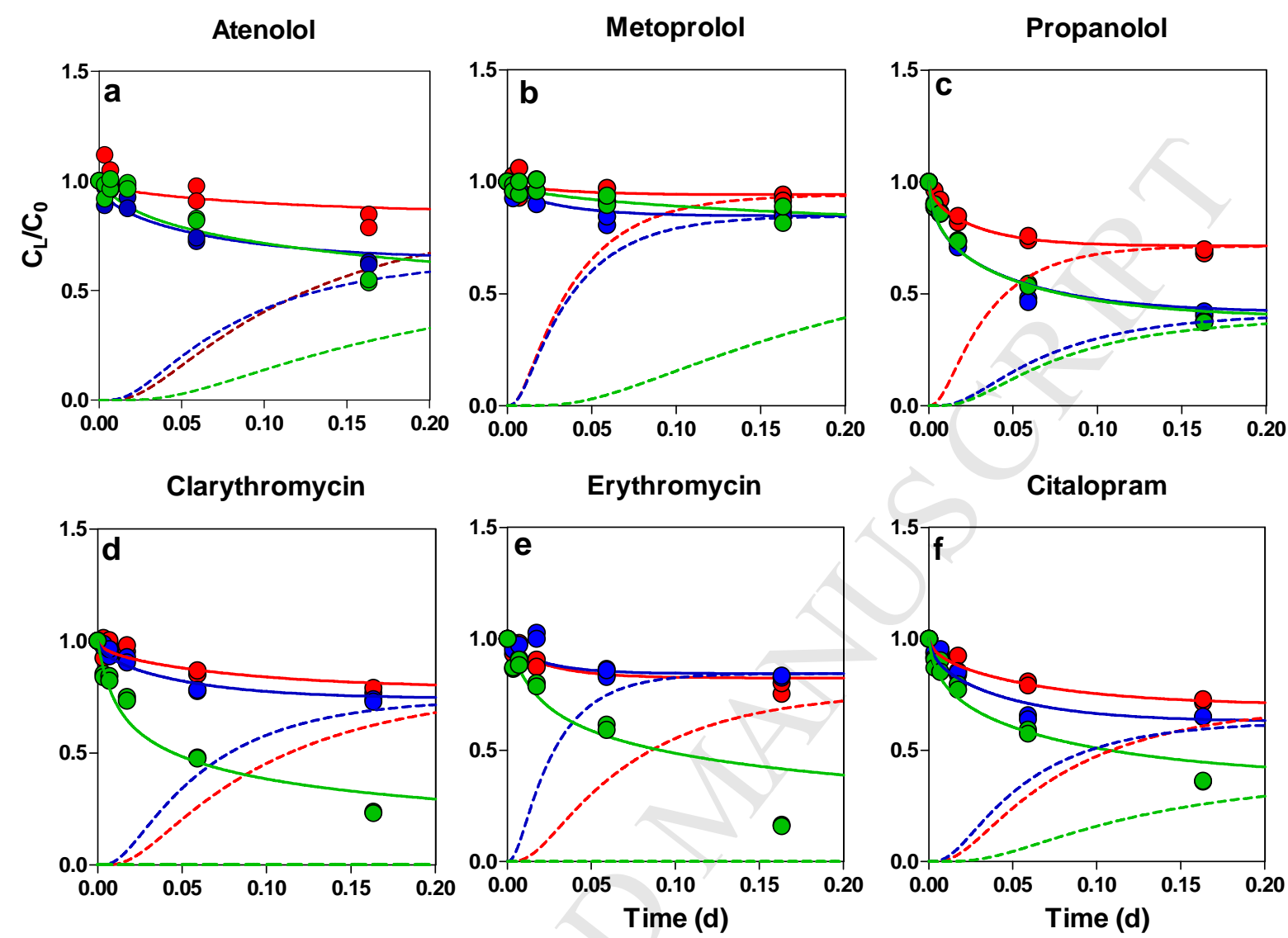

Figure 3. Measured (technical replicates, in circles) and simulated (continuous line) aqueous concentrations $C_{L}$ in bulk aqueous phase (normalized over initial aqueous concentration $C_{L, 0}$ ) and simulated concentrations in biofilm pores liquid (dashed lines) of six selected chemicals compounds during batch experiments with Z50 (red), Z200 (blue) and Z500 (green) biofilms. Simulated $C_{L}$ in biofilm denotes the aqueous concentration in the deepest layer of the discretized biofilm (section 2.1). 


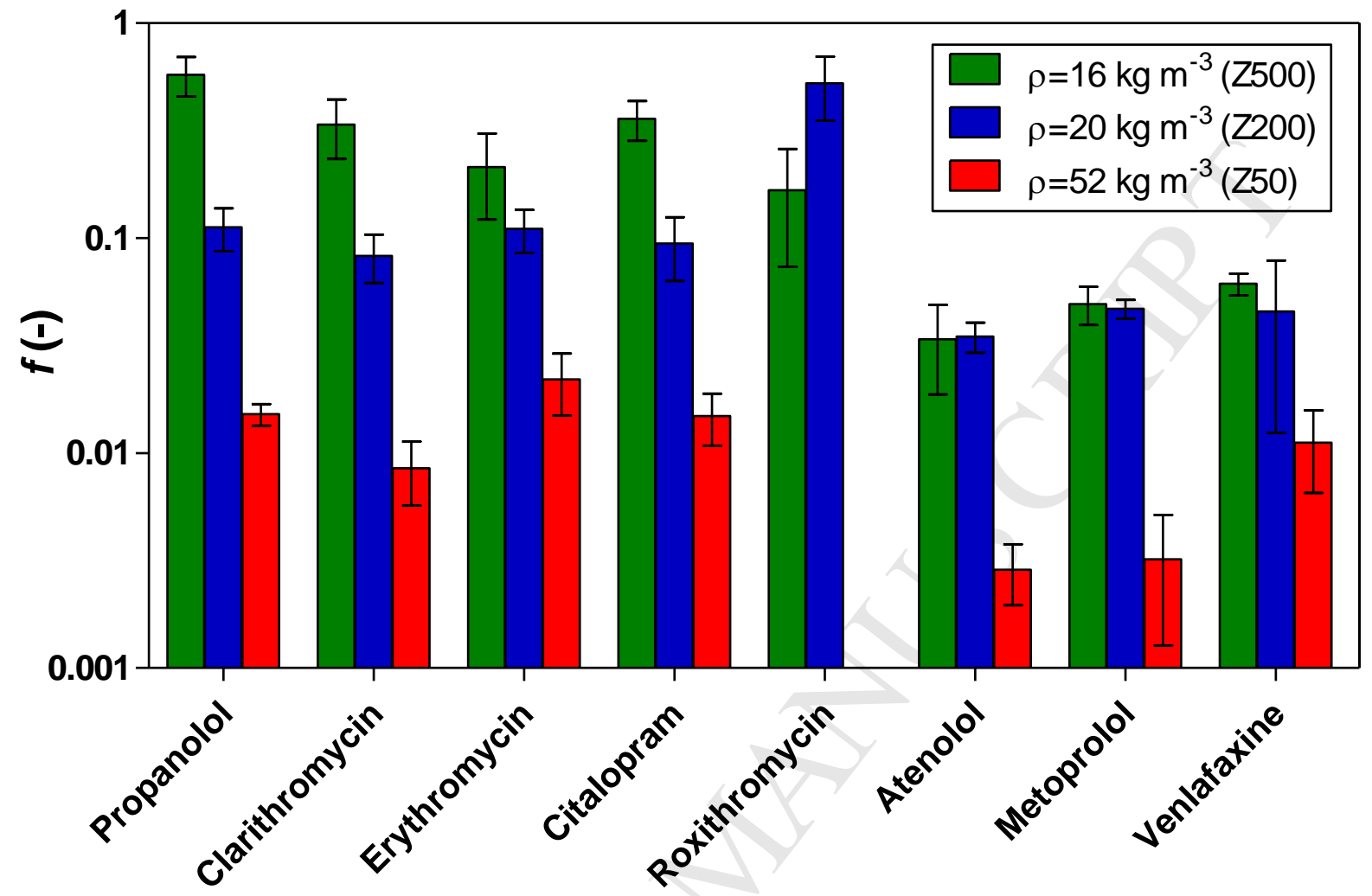

Figure 4. Estimated values of dimensionless effective diffusivity $f$ for the three biofilm thicknesses and the eight chemicals - showing significant sorption - by calibrating the diffusion-sorption model. 


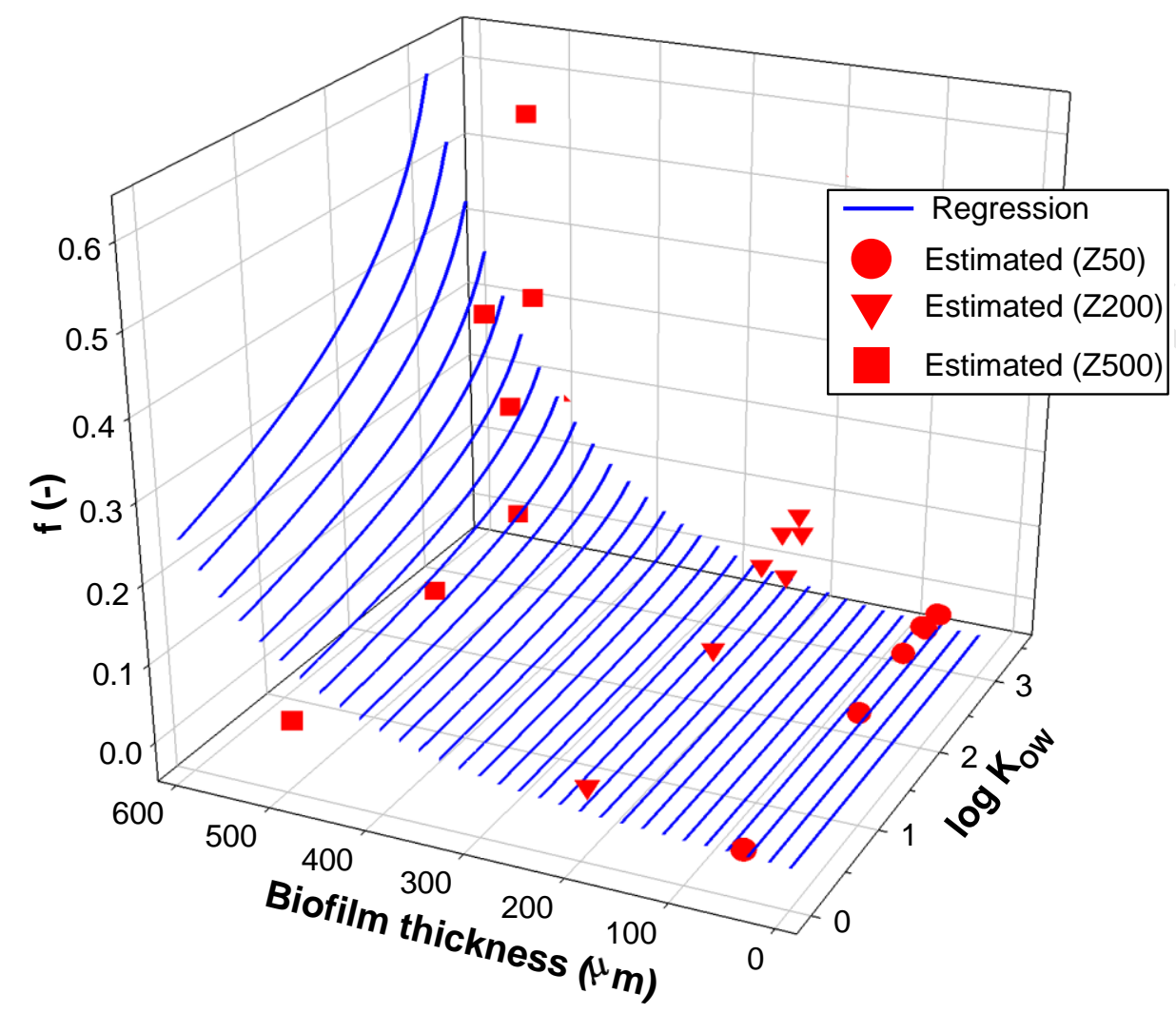

2 Figure 5. Plots of the empirical equation describing $f$-for atenolol, erythromycin, metoprolol,

3 propranolol, clarithromycin, roxithromycin, citalopram, venlafaxine - as a function of biofilm

4 thickness and $\log K_{\text {ow }}$, together with estimated $f$ values (red symbols) in Z50, Z200 and Z500. 

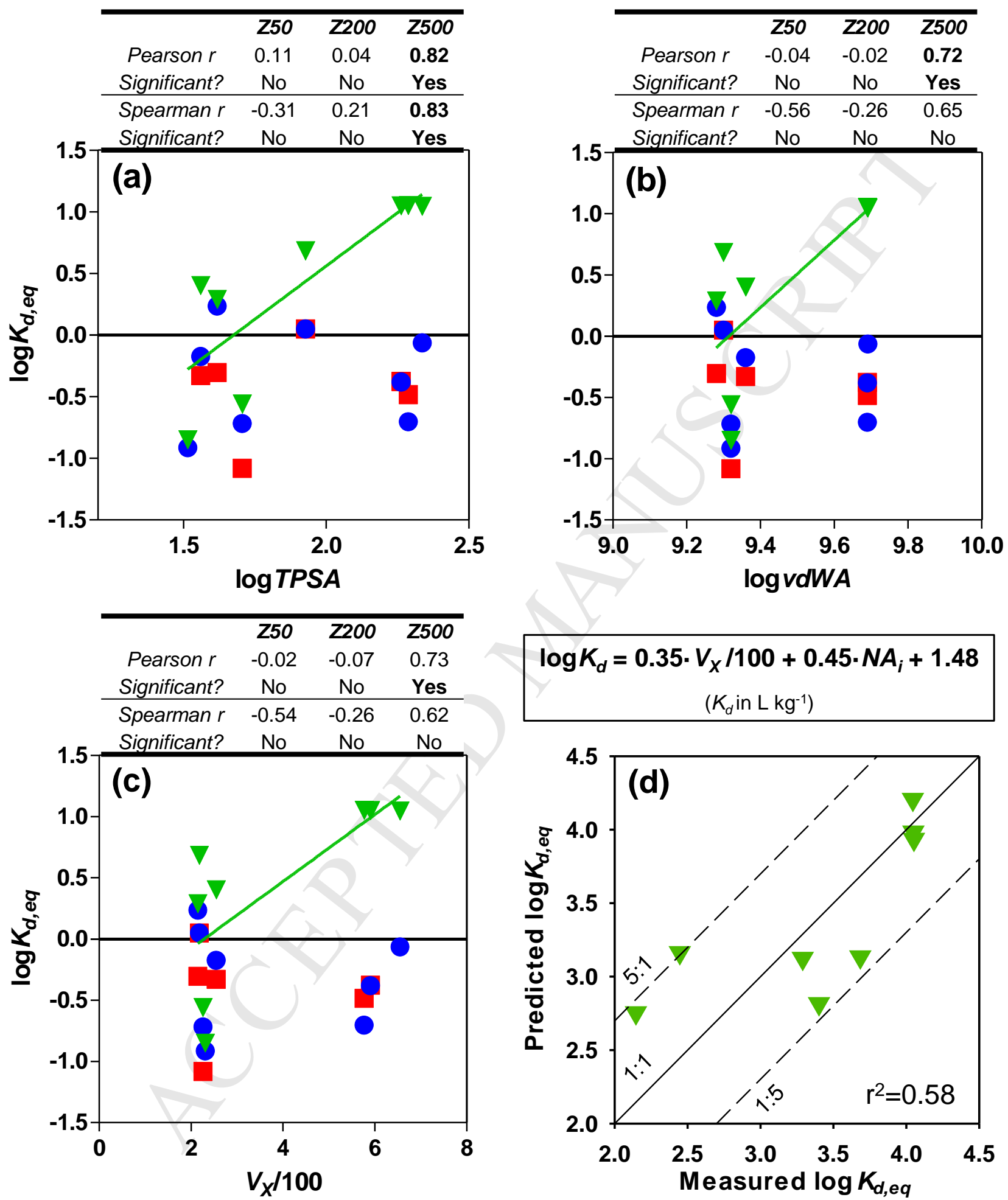

$$
\begin{gathered}
\log K_{d}=\mathbf{0 . 3 5} \cdot V_{X} / 100+\mathbf{0 . 4 5} \cdot \mathbf{N A}_{\boldsymbol{i}}+\mathbf{1 . 4 8} \\
\left(K_{d} \mathrm{in} \mathrm{L} \mathrm{kg}{ }^{-1}\right)
\end{gathered}
$$

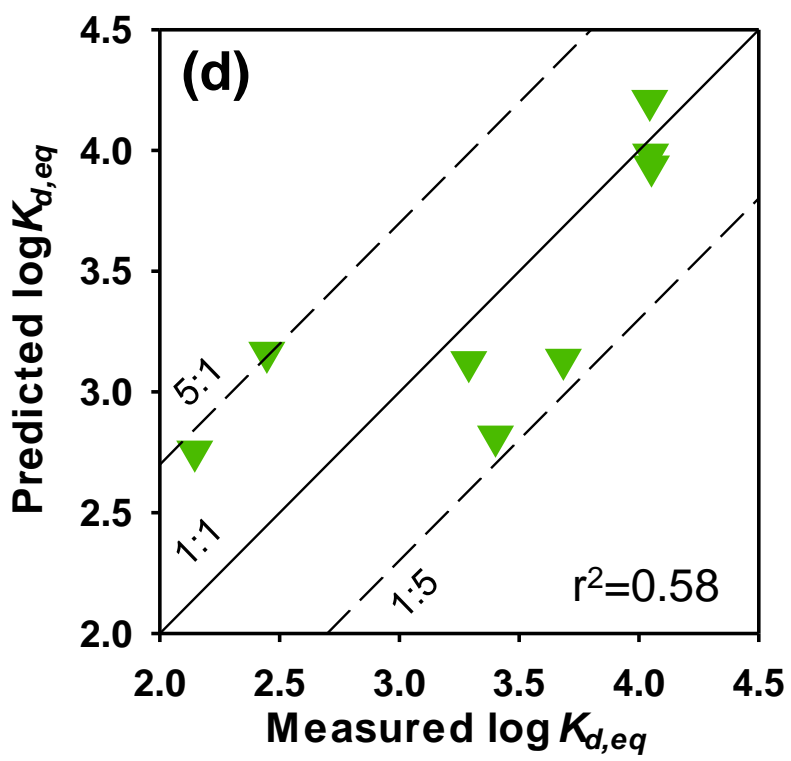

$\begin{array}{lllll}Z 50 & \bullet & Z 200 & \nabla & Z 500\end{array}$ 
Figure 6. Correlation analysis between $\log K_{d, e q}$ of the targeted micropollutants for the three biofilms (Z50, Z200, Z500) and physico-chemical descriptors: (a) $\log T P S A$; (b) $\log v d W A$; (c) McGowan's volume $V_{X}$ (divided by a factor of 100). Linear regression lines were reported only for significant correlations. Based on the correlation with $V_{X} / 100$, an empirical regression (Eq. 8) was tested according to Droge and Goss $(2013 \mathrm{a}, \mathrm{c})$. The comparison between measurements and predictions using Eq. 8 (in both cases, with $K_{d, e q}$ in $\mathrm{L} \mathrm{kg}^{-1}$ ) is presented in (d). 


\section{Highlights}

- Diffusion-sorption of pharmaceuticals assessed in biofilms of different thicknesses

- Sorption significant only for eight positively ionized compounds

- Sorption coefficients increased with increasing biofilm thickness

- Several days necessary to reach partitioning equilibrium in thicker biofilms

- Effective diffusivity in biofilm negatively influenced by biofilm density 


\section{Supplementary Information for:}

\section{Diffusion and sorption of organic micropollutants in}

\section{biofilms with varying thicknesses}

Elena Torresi ${ }^{1,2 \dagger^{* *}}$, Fabio Polesel ${ }^{1 \dagger}$, Kai Bester ${ }^{3}$, Magnus Christensson ${ }^{2}$, Barth F. Smets ${ }^{1}$, Stefan Trapp ${ }^{1}$, Henrik R. Andersen ${ }^{1}$, Benedek Gy. Plósz ${ }^{1,4} *$

${ }^{1}$ DTU Environment, Technical University of Denmark, Bygningstorvet B115, 2800 Kongens Lyngby, Denmark

${ }^{2}$ Veolia Water Technologies AB, AnoxKaldnes, Klosterängsvägen 11A, SE-226 47 Lund, Sweden

${ }^{3}$ Department of Environmental Science, Århus University, Frederiksborgvej 399, 4000 Roskilde, Denmark

${ }^{4}$ Department of Chemical Engineering, University of Bath, Claverton Down, Bath BA2 7AY, UK

$\dagger$ The authors equally contributed to this manuscript.

*Benedek Gy. Plósz: b.g.plosz@bath.ac.uk

**Elena Torresi: elto@env.dtu.dk 


\section{Supplementary Tables}

Table S1. Diffusivity coefficients in water $\left(D_{\mathrm{W}}\right)$ of the substances exhibiting sorption, estimated according to different methods from literature (see equations below).

\begin{tabular}{|c|c|c|c|c|c|c|}
\hline & \multirow{2}{*}{$\begin{array}{c}\text { Hayduk and } \\
\text { Laudie (1974) }\end{array}$} & \multirow{2}{*}{$\begin{array}{c}\text { Wilke and } \\
\text { Chang (1955) }\end{array}$} & \multicolumn{2}{|c|}{$\begin{array}{c}D_{W, i}\left(m^{2} d^{-1}\right) \\
\text { Schwarzenbach et al. } \\
(\mathbf{2 0 0 3 )}\end{array}$} & \multirow{2}{*}{$\begin{array}{l}\text { Trapp and } \\
\text { Matthies } \\
(1998)\end{array}$} & \multirow{2}{*}{$\begin{array}{l}\text { Sitaraman et } \\
\text { al. (1963) }\end{array}$} \\
\hline & & & I & II & & \\
\hline Atenolol & $4.57 \cdot 10^{-5}$ & $4.82 \cdot 10^{-5}$ & $4.39 \cdot 10^{-5}$ & $4.10 \cdot 10^{-5}$ & $7.63 \cdot 10^{-5}$ & $2.72 \cdot 10^{-5}$ \\
\hline Erythromycin & $2.62 \cdot 10^{-5}$ & $2.74 \cdot 10^{-5}$ & $2.52 \cdot 10^{-5}$ & $2.10 \cdot 10^{-5}$ & $4.59 \cdot 10^{-5}$ & $1.75 \cdot 10^{-5}$ \\
\hline Metoprolol & $4.33 \cdot 10^{-5}$ & $4.57 \cdot 10^{-5}$ & $4.16 \cdot 10^{-5}$ & $3.85 \cdot 10^{-5}$ & $7.61 \cdot 10^{-5}$ & $2.61 \cdot 10^{-5}$ \\
\hline Propranolol & $4.56 \cdot 10^{-5}$ & $4.81 \cdot 10^{-5}$ & $4.38 \cdot 10^{-5}$ & $4.09 \cdot 10^{-5}$ & $7.73 \cdot 10^{-5}$ & $2.72 \cdot 10^{-5}$ \\
\hline Clarithromycin & $2.56 \cdot 10^{-5}$ & $2.67 \cdot 10^{-5}$ & $2.46 \cdot 10^{-5}$ & $2.04 \cdot 10^{-5}$ & $4.55 \cdot 10^{-5}$ & $1.72 \cdot 10^{-5}$ \\
\hline Citalopram & $4.20 \cdot 10^{-5}$ & $4.43 \cdot 10^{-5}$ & $4.04 \cdot 10^{-5}$ & $3.71 \cdot 10^{-5}$ & $6.91 \cdot 10^{-5}$ & $2.55 \cdot 10^{-5}$ \\
\hline Venlafaxine & $4.31 \cdot 10^{-5}$ & $4.54 \cdot 10^{-5}$ & $4.13 \cdot 10^{-5}$ & $3.82 \cdot 10^{-5}$ & $7.47 \cdot 10^{-5}$ & $2.59 \cdot 10^{-5}$ \\
\hline Roxithromycin & $2.48 \cdot 10^{-5}$ & $2.59 \cdot 10^{-5}$ & $2.38 \cdot 10^{-5}$ & $1.97 \cdot 10^{-5}$ & $4.30 \cdot 10^{-5}$ & $1.68 \cdot 10^{-5}$ \\
\hline
\end{tabular}

Equations

Hayduk and Laudie (1974):

$$
D_{W, M P}=13.26 \cdot 10^{-5} /\left(\eta^{1.14} M V_{M P}^{0.589}\right)
$$

Wilke and Chang (1955):

$$
D_{W, M P}=7.4 \cdot 10^{-8} x M W^{0.5} T /\left(\eta M V_{M P}^{0.6}\right)
$$

Schwarzenbach et al. (2003) - I:

$D_{W, M P}=D_{W, r e f}\left(M V_{\text {ref }} / M V_{M P}\right)^{0.589}$

Schwarzenbach et al. (2003) - II:

$D_{W, M P}=2.3 \cdot 10^{-4} / M V_{M P}^{0.71}$

Trapp and Matthies (1998):

$D_{W, M P}=D_{W, r e f}\left(M W_{r e f} / M W_{M P}\right)^{0.5}$

Sitaraman et al. (1963):

$D_{W, M P}=5.4 \cdot 10^{-8} M W^{0.5} T L_{S}^{1 / 3} /\left(\eta L_{S}^{0.3} M V_{M P}^{0.6}\right)$

where $D_{W, M P}=$ diffusivity of micropollutant $\left(=D_{W, i}\right), \eta=$ viscosity of solvent/solution, $M V_{M P}=$ molecular volume of the micropollutant, $M W_{M P}=$ molecular weight of the micropollutant, $T=$ temperature, $D_{W, r e f}=$ diffusivity coefficient of reference substance, $M V_{\text {ref }}=$ molecular volume of the reference substance, $M W_{\text {ref }}=$ molecular weight of the reference substance, $L_{S}=$ latent heat of vaporization of solvent at boiling point. Where required, oxygen was considered as reference substance $\left(D_{W, O 2}=2.2 \cdot 10^{-4} \mathrm{~m}^{2} \mathrm{~d}^{-1}\right.$; Torresi et al., 2016). For measurement units of the different parameters, the reader is referred to the original publications. 
Table S2. Physico-chemical properties of the micropollutants investigated in this study and for which sorption to MBBR biofilms was observed. Properties were estimated with $\mathrm{ACD} / \mathrm{Labs}$ except for $V_{X}$ (calculated according to Abraham and McGowan, 1987).

\begin{tabular}{|c|c|c|c|c|c|c|c|c|c|}
\hline Compound & Formula & Structure & $\begin{array}{c}\text { McGowan's } \\
V_{X} \\
\left(\mathrm{~cm}^{3} \mathrm{~mol}^{-1}\right)\end{array}$ & $\begin{array}{c}\text { Molecular } \\
\text { volume } \\
M V \\
\left(\mathrm{~cm}^{3} \mathrm{~mol}^{-1}\right) \\
\end{array}$ & $\begin{array}{c}\text { Molecular } \\
\text { weight } \\
M W \\
\left(\mathrm{~g} \mathrm{~mol}^{-1}\right) \\
\end{array}$ & $\log K_{O W}$ & $\log D$ & $p K_{a}$ & Ref \\
\hline Atenolol & $\mathrm{C}_{14} \mathrm{H}_{22} \mathrm{~N}_{2} \mathrm{O}_{3}$ & & 217.6 & 236.6 & 266.34 & 0.1 & -1.87 & $\begin{array}{c}9.5 \\
\text { (base) }\end{array}$ & $\mathrm{ACD}$ \\
\hline Metoprolol & $\mathrm{C}_{15} \mathrm{H}_{25} \mathrm{NO}_{3}$ & & 26.0 & 258.7 & 267.36 & 1.79 & 0.08 & $\begin{array}{c}9.5 \\
\text { (base) }\end{array}$ & $\mathrm{ACD}$ \\
\hline Propranolol & $\mathrm{C}_{16} \mathrm{H}_{21} \mathrm{NO}_{2}$ & & 214.8 & 237.1 & 259.34 & 3.1 & 0.96 & $\begin{array}{c}9.5 \\
\text { (base) }\end{array}$ & $\mathrm{ACD}$ \\
\hline Clarithromycin & $\mathrm{C}_{38} \mathrm{H}_{69} \mathrm{NO}_{13}$ & & 591.4 & 631.9 & 747.9 & 3.16 & 2.12 & $\begin{array}{c}8.5 \\
\text { (base) }\end{array}$ & $\mathrm{ACD}$ \\
\hline
\end{tabular}


ACCEPTED MANUSCRIPT

\begin{tabular}{|c|c|c|c|c|c|c|c|c|}
\hline Erythromycin & $\mathrm{C}_{37} \mathrm{H}_{67} \mathrm{NO}_{13}$ & 577.3 & 607.1 & 733.9 & 2.83 & 1.42 & $\begin{array}{c}8.6 \\
\text { (base) }\end{array}$ & $\mathrm{ACD}$ \\
\hline Roxithromycin & $\mathrm{C}_{41} \mathrm{H}_{76} \mathrm{~N}_{2} \mathrm{O}_{15}$ & 655.4 & 666.3 & & 3.73 & 2.24 & $\begin{array}{c}8.6 \\
\text { (base) }\end{array}$ & ACD \\
\hline Citalopram & $\mathrm{C}_{20} \mathrm{H}_{21} \mathrm{FN}_{2} \mathrm{O}$ & 255.3 & 272.6 & 324.39 & 2.51 & 2.06 & $\begin{array}{c}9.4 \\
\text { (base) }\end{array}$ & ACD \\
\hline Venlafaxine & $\mathrm{C}_{17} \mathrm{H}_{27} \mathrm{NO}_{2}$ & 237 & 261.6 & 277.4 & 2.91 & 2.59 & $\begin{array}{c}8.4 \\
\text { (base) }\end{array}$ & $\mathrm{ACD}$ \\
\hline
\end{tabular}


Table S3. Ionization properties and prevailing ionization state at experimental $\mathrm{pH}(=7.5)$ of all the micropollutants investigated in this study. Reported $p K_{a}$ values are the ones relevant to typical wastewater $\mathrm{pH}$. The chemicals, for which sorption to biofilms was observed, are presented in italics.

\begin{tabular}{|c|c|c|c|}
\hline Compound & $p K_{a}$ & $\begin{array}{l}\text { Charge and ionic } \\
\text { fraction at } \mathrm{pH}=7.5\end{array}$ & Reference \\
\hline Acetyl-sulfadiazine & $\begin{array}{l}6.99 \text { (acid) } \\
2.01 \text { (base) } \\
\end{array}$ & $\begin{array}{l}76 \% \text { negative, } \\
0 \% \text { positive }\end{array}$ & ChemAxon \\
\hline Sulfadiazine & $\begin{array}{l}6.5 \text { (acid) } \\
2.1 \text { (base) }\end{array}$ & $\begin{array}{l}91 \% \text { negative, } \\
0 \% \text { positive }\end{array}$ & \\
\hline Sulfamethizole & $\begin{array}{l}5.3 \text { (acid) } \\
1.8 \text { (base) }\end{array}$ & $\begin{array}{l}99 \% \text { negative, } \\
0 \% \text { positive }\end{array}$ & ACD \\
\hline Sulfamethoxazole & $\begin{array}{l}5.7 \text { (acid) } \\
1.8 \text { (base) }\end{array}$ & $\begin{array}{l}98 \% \text { negative, } \\
0 \% \text { positive }\end{array}$ & ACD \\
\hline Trimethoprim & 7.0 (base) & $24 \%$ positive & $\mathrm{ACD}$ \\
\hline Atenolol & 9.5 (base) & $99 \%$ positive & $\mathrm{ACD}$ \\
\hline Metoprolol & 9.5 (base) & $99 \%$ positive & $\mathrm{ACD}$ \\
\hline Propranolol & 9.5 (base) & $99 \%$ positive & ACD \\
\hline Sotalol & $\begin{array}{l}8.3 \text { (base) } \\
10.1 \text { (acid) } \\
\end{array}$ & $\begin{array}{l}86 \% \text { positive } \\
13 \% \text { zwitterionic }\end{array}$ & ACD \\
\hline Clarithromycin & 8.5 (base) & $92 \%$ positive & $\mathrm{ACD}$ \\
\hline Erythromycin & 8.6 (base) & $92 \%$ positive & $\mathrm{ACD}$ \\
\hline Roxithromycin & 8.6 (base) & $92 \%$ positive & $\mathrm{ACD}$ \\
\hline Diclofenac & 4.0 (acid) & $100 \%$ negative & $\mathrm{ACD}$ \\
\hline Phenazone & 1.8 (base) & $0 \%$ positive & $\mathrm{ACD}$ \\
\hline Carbamazepine & Neutral & & $\mathrm{ACD}$ \\
\hline Citalopram & 9.4 (base) & $99 \%$ positive & ACD \\
\hline Venlafaxine & 8.4 (base) & $90 \%$ positive & $\mathrm{ACD}$ \\
\hline Diatrizoic acid & 1.4 (acid) & $100 \%$ negative & $\mathrm{ACD}$ \\
\hline Iohexol & 11.8 (acid) & $0 \%$ negative & $\mathrm{ACD}$ \\
\hline Iomeprol & 11.8 (acid) & $0 \%$ negative & $\mathrm{ACD}$ \\
\hline Iopamidol & 10.8 (acid) & $0 \%$ negative & $\mathrm{ACD}$ \\
\hline Iopromide & 10.6 (acid) & $0 \%$ negative & $\mathrm{ACD}$ \\
\hline
\end{tabular}


Table S4. Comparison between $K_{d, s u s p}$ (Eq. 6) and $K_{d, e q}$ (Eq. 3), calculated using the estimated asymptotic equilibrium concentration $C_{L, e q}$. The relative deviation $\Delta(\%)$ between $K_{d, s u s p}$ and $K_{d, e q}$ is used to assess the impact of porosity on sorption coefficient estimation, i.e. the overestimation of the sorption coefficient by neglecting transport of micropollutants from bulk aqueous phase to biofilm pores.

\begin{tabular}{|c|c|c|c|c|c|c|c|c|c|}
\hline & \multicolumn{3}{|c|}{$Z 50$} & \multicolumn{3}{|c|}{$Z 200$} & \multicolumn{3}{|c|}{$Z 500$} \\
\hline & $\begin{array}{l}K_{d, \text { susp }} \\
\left(\mathbf{L} \mathbf{g}^{-1}\right)\end{array}$ & $\begin{array}{c}K_{d, e q} \\
\left(\mathbf{L} \mathbf{g}^{-1}\right)\end{array}$ & $\underset{(\%)}{\Delta}$ & $\begin{array}{l}K_{d, s u s p} \\
\left(\mathbf{L} \mathbf{g}^{-1}\right)\end{array}$ & $\begin{array}{c}K_{d, e q} \\
\left(\mathbf{L} \mathbf{g}^{-1}\right)\end{array}$ & $\begin{array}{c}\Delta \\
(\%) \\
\end{array}$ & $\begin{array}{c}\boldsymbol{K}_{d, \text { susp }} \\
\left(\mathbf{L} \mathbf{g}^{-1}\right)\end{array}$ & $\begin{array}{c}K_{d, e q} \\
\left(\mathbf{L} \mathbf{g}^{-1}\right)\end{array}$ & $\begin{array}{c}\Delta \\
(\%)\end{array}$ \\
\hline Atenolol & 1.15 & 1.12 & 3 & 1.21 & 1.12 & 8 & 5.15 & 4.84 & 6 \\
\hline Metoprolol & 0.10 & 0.08 & 16 & 0.25 & 0.19 & 22 & 0.35 & 0.28 & 21 \\
\hline Propranolol & 0.52 & 0.50 & 4 & 1.83 & 1.71 & 6 & 2.11 & 1.95 & 8 \\
\hline Clarithromycin & 0.44 & 0.42 & 5 & 0.48 & 0.41 & 13 & 11.82 & 11.19 & 5 \\
\hline Erythromycin & 0.35 & 0.33 & 6 & 0.25 & 0.20 & 22 & 11.91 & 11.28 & 5 \\
\hline Roxithromycin & 0.00 & 0.00 & I & & 0.86 & 9 & 11.73 & 11.10 & 5 \\
\hline Citalopram & 0.49 & 0.47 & 5 & 0.74 & 0.67 & 10 & 2.71 & 2.52 & 7 \\
\hline Venlafaxine & 0.03 & 0.00 & 100 & 0.17 & 0.12 & 30 & 0.21 & 0.14 & 33 \\
\hline
\end{tabular}


Table S5. Goodness of fit $\left(\mathrm{R}^{2}\right)$ for the sorption-diffusion biofilm model, calculated by comparing measured and simulated data

\begin{tabular}{llll}
\hline & \multicolumn{2}{c}{$\mathbf{R}^{\mathbf{2}}$} \\
& $\mathbf{Z 5 0}$ & $\mathbf{Z 2 0 0}$ & $\mathbf{Z 5 0 0}$ \\
\hline Atenolol & 0.85 & 0.94 & 0.85 \\
\hline Metoprolol & 0.96 & 0.83 & 0.93 \\
\hline Propranolol & 0.99 & 0.97 & 0.98 \\
\hline Clarithromycin & 0.93 & 0.97 & 0.94 \\
\hline Erythromycin & 0.95 & 0.99 & 0.88 \\
\hline Citalopram & 0.99 & 0.94 & 0.97 \\
\hline Venlafaxine & $/$ & 0.89 & 0.98 \\
\hline Roxithromycin & $/$ & 0.94 & 0.88 \\
\hline
\end{tabular}


Table S6. Proposed models for biofilm diffusivities used in estimates validation

\begin{tabular}{|c|c|c|c|}
\hline Diffusion model & Relation & Additional info & Range \\
\hline $\begin{array}{l}\text { Zhang and Bishop } \\
\text { (1994) }\end{array}$ & $f=\varepsilon^{3}$ & $\varepsilon=1-\frac{X_{b}}{\rho_{C E L L}}$ & $8 \%<\varepsilon<92 \%$ \\
\hline $\begin{array}{l}\text { Hinson and Kocher } \\
\text { (1996) }\end{array}$ & $f=\frac{2 \cdot\left(1-\varepsilon_{o}\right) \cdot \varepsilon_{w}}{\left(2+\varepsilon_{o}\right) \cdot\left(\varepsilon_{w}+\frac{\varepsilon_{p}}{D_{p r}}\right)}$ & & \\
\hline $\begin{array}{l}\text { Beyenal et al. } \\
\text { (1997) }\end{array}$ & $f=10^{-0.0072367 X_{b}}$ & & \\
\hline $\begin{array}{l}\text { Horn and } \\
\text { Morgenroth (2006) }\end{array}$ & $f=1.112-0.019 \cdot X_{b}$ & & $10<X_{b}<20$ \\
\hline
\end{tabular}

Where $f$ is the dimensionless diffusivity within biofilms, $X_{b}\left(\mathrm{~kg} \mathrm{~m}^{-3}\right)$ is the biofilm density, $\varepsilon$ is the biofilm porosity, $\rho_{C E L L}$ is the cells density $\left(250 \mathrm{~kg} \cdot \mathrm{m}^{-3}\right.$ (Zhang and Bishop, 1994a)), $\varepsilon_{o}$ is cells volume fraction, $\rho_{o}$ is the cells density, $\varepsilon_{\mathrm{p}}$ is the extra polymeric substances (EPS) volume fraction, $\rho_{p}$ is the EPS density (considered equal to $\rho_{0}$ (Hinson and Kocher, 1996)), $\varepsilon_{w}$ is the water volume fraction, and $D_{p r}$ is the relative diffusivity within EPS (0.022 (Hinson and Kocher, 1996). 


\section{Supplementary Figures}
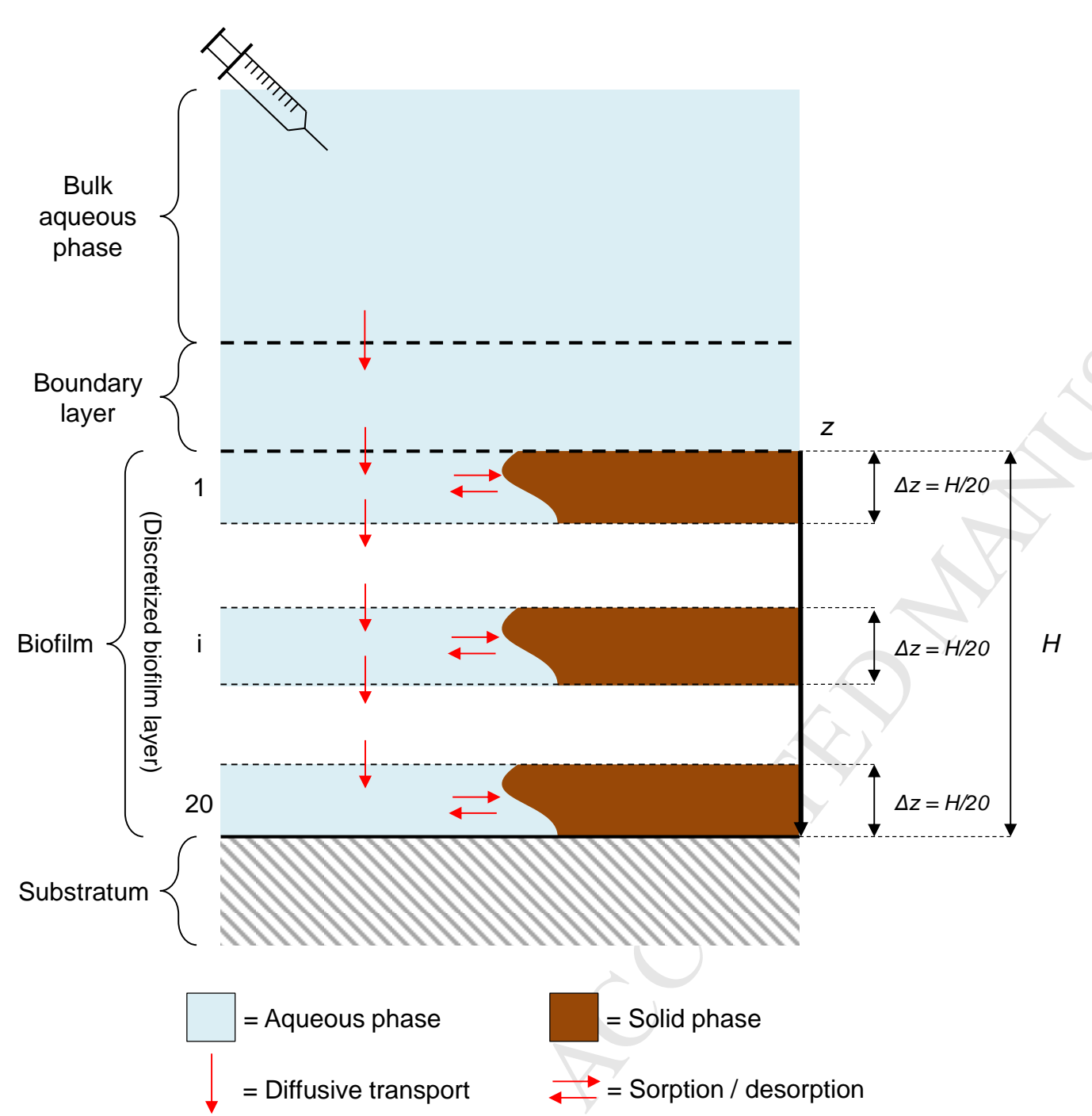

Mass balances

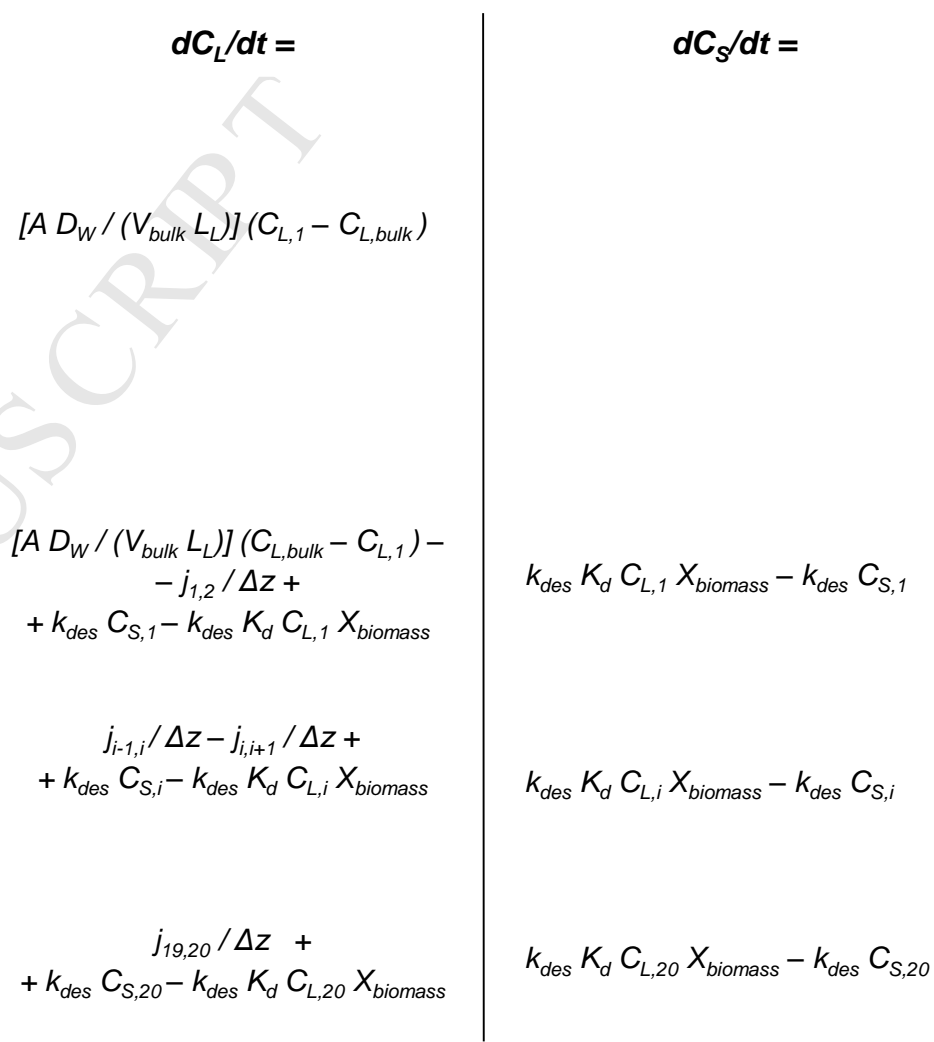

\section{Initial conditions}

$C_{L, \text { bulk }}=C_{L}$ measured at $t=0$

$$
\begin{aligned}
& C_{L, i}(i=1: 20)=0 \\
& C_{S, i}(i=1: 20)=0
\end{aligned}
$$

Figure S1. Conceptual representation of the biofilm model implemented in Aquasim, with mass balances for bulk aqueous phase and selected biofilm layers and initial conditions for the state variables $C_{L}$ and $C_{S}$ in the different compartments. 

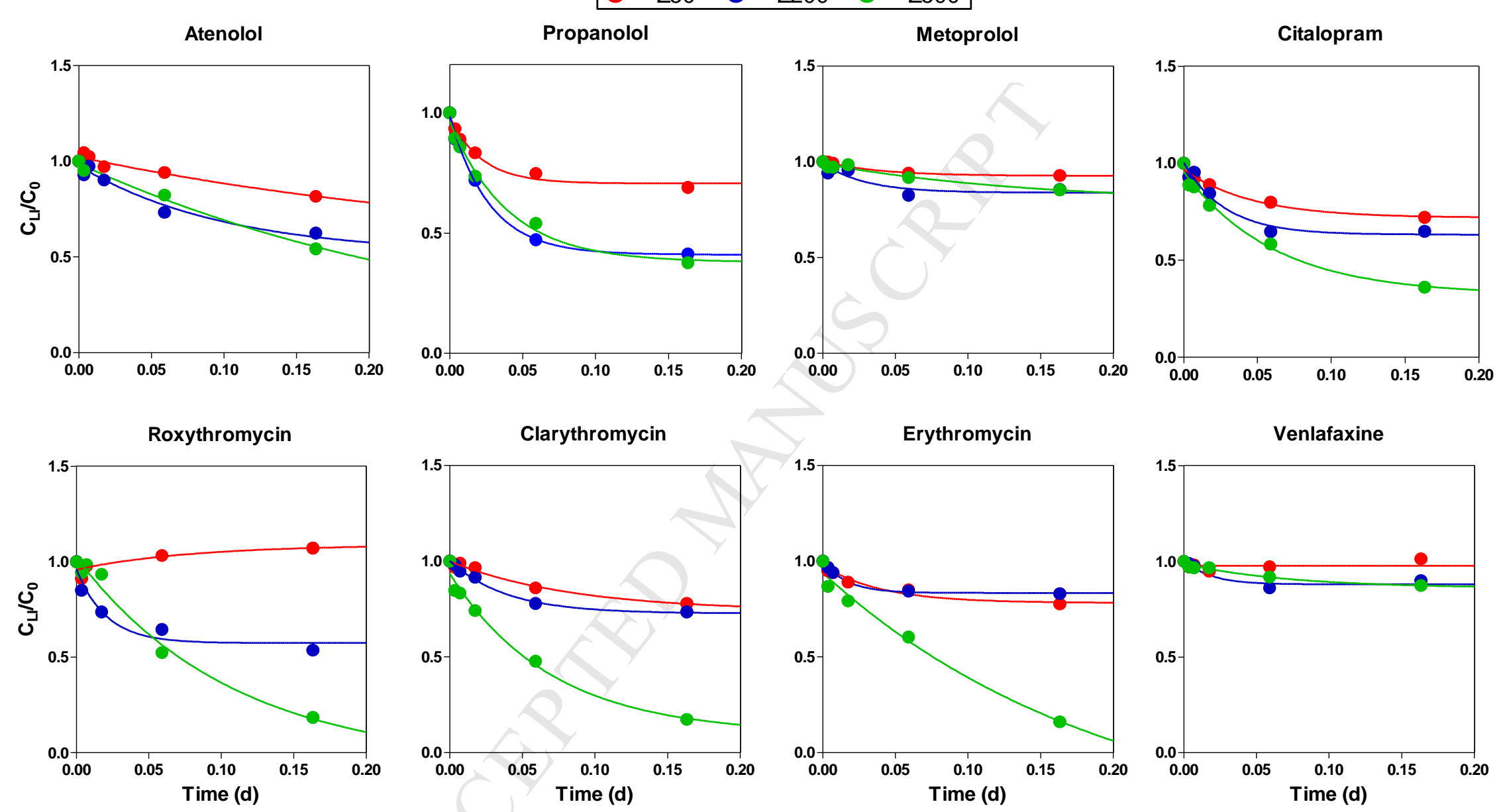

Figure S2. Model fit (continuous lines) of experimental data (circles) using first-order kinetics asymptotic function (Eq. 4) for the calculation of $K_{d, e q}$. 


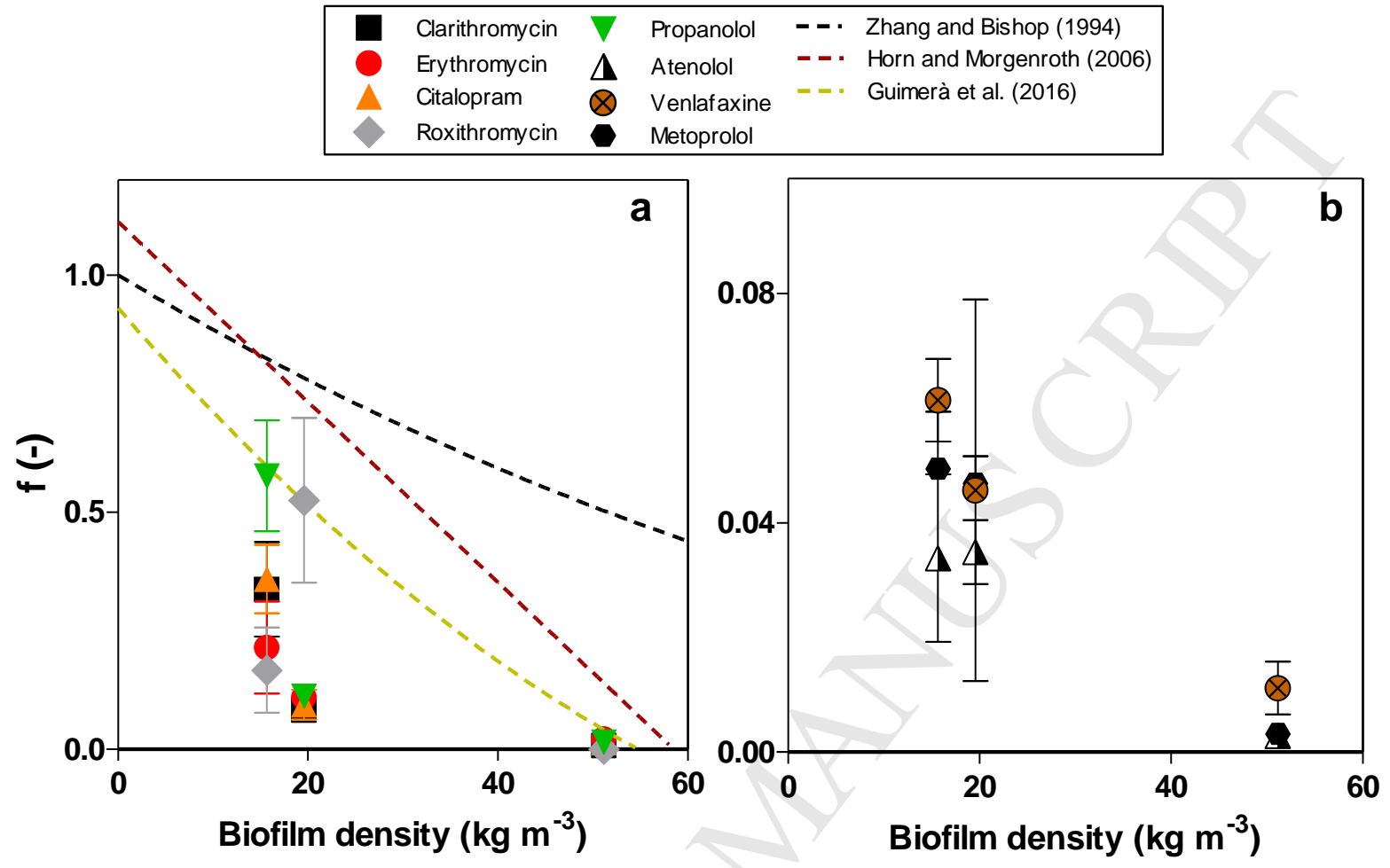

Figure S3. Estimated values of effective diffusivity cofficient $f$ for the targeted micropollutants and regression correlation between $\mathrm{f}$ and biofilm density reported in literature. 

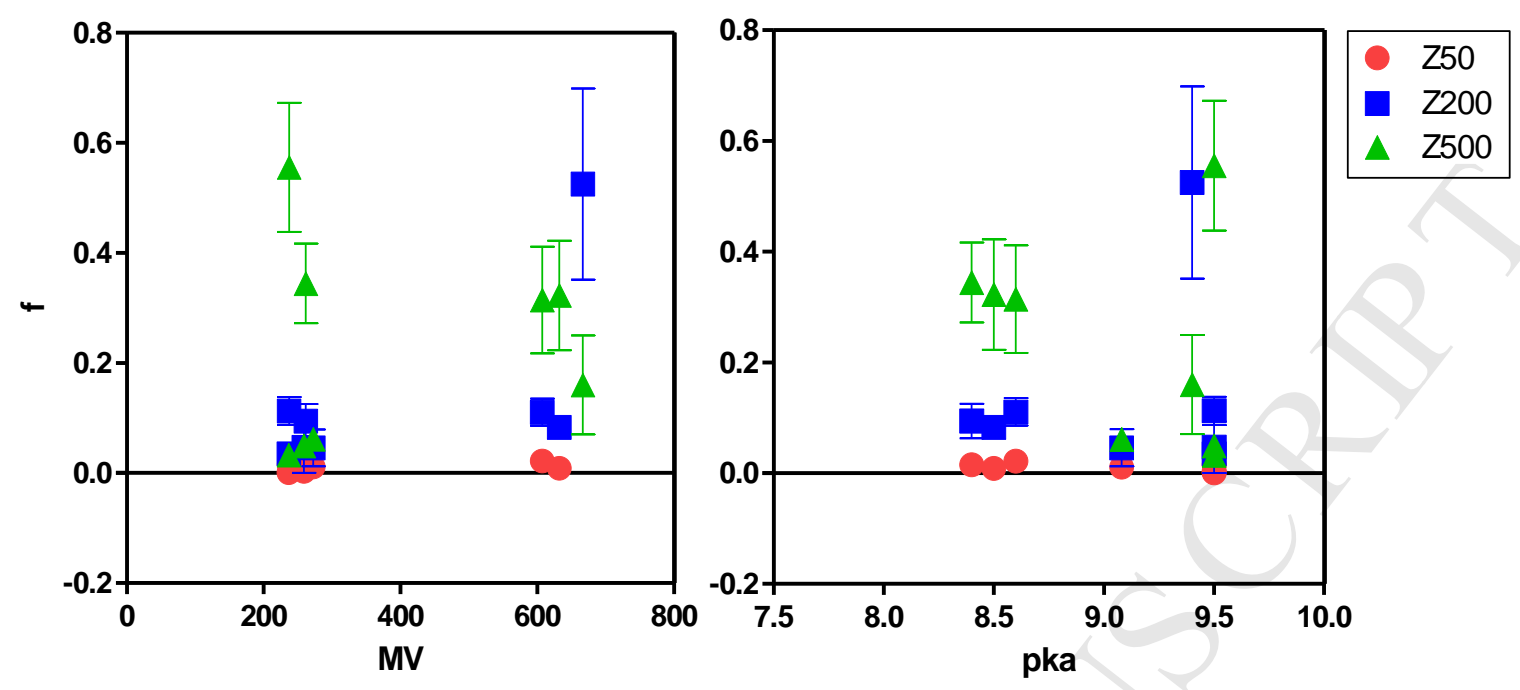

Figure S4. Estimated effective diffusivity factor $(f)$ plotted as a function of molecular volume $(M V)$ and dissociation constant $\left(p K_{a}\right)$ of the compounds, exhibiting sorption to biofilm. 


\section{$\mathrm{Y}=\left(\mathrm{Y}_{0}-\mathrm{b}\right)^{*} \exp \left(-\mathrm{K}^{*} \mathrm{X}\right)+\mathrm{b}$}

$\mathrm{Z} 50$
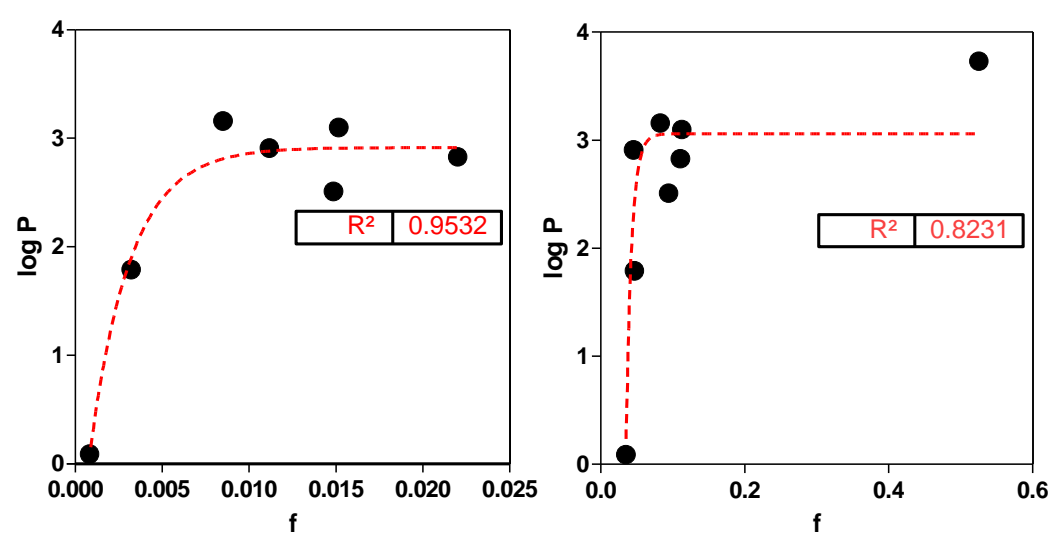

Z500

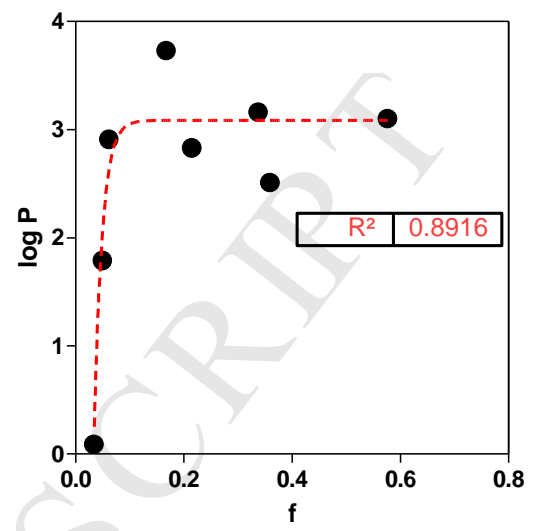

\begin{tabular}{lllllll}
\hline & Y0 & SE Y0 & b & SE b & K & SE K \\
\hline Z50 & -1.13 & 0.67 & 2.92 & 0.14 & 430.40 & 134.60 \\
Z200 & -249.40 & 526.10 & 3.06 & 0.25 & 127.50 & 29.79 \\
Z500 & -26.56 & 18.49 & 3.09 & 0.20 & 67.43 & 58.93 \\
\hline
\end{tabular}
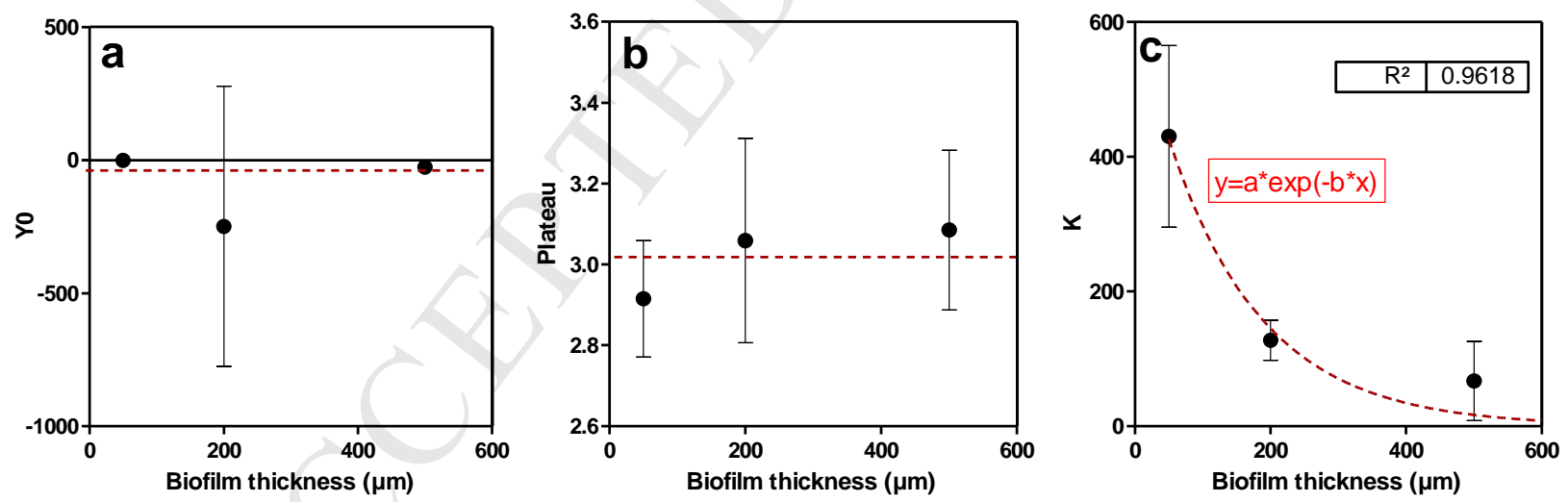

Figure S5. Summary of the regression, describing the diffusivity reduction factor $f$ as a function of $\log K_{O W}(\log P)$ of the chemical and biofilm thickness. Error bars indicate standard errors of the estimated regression coefficients. 

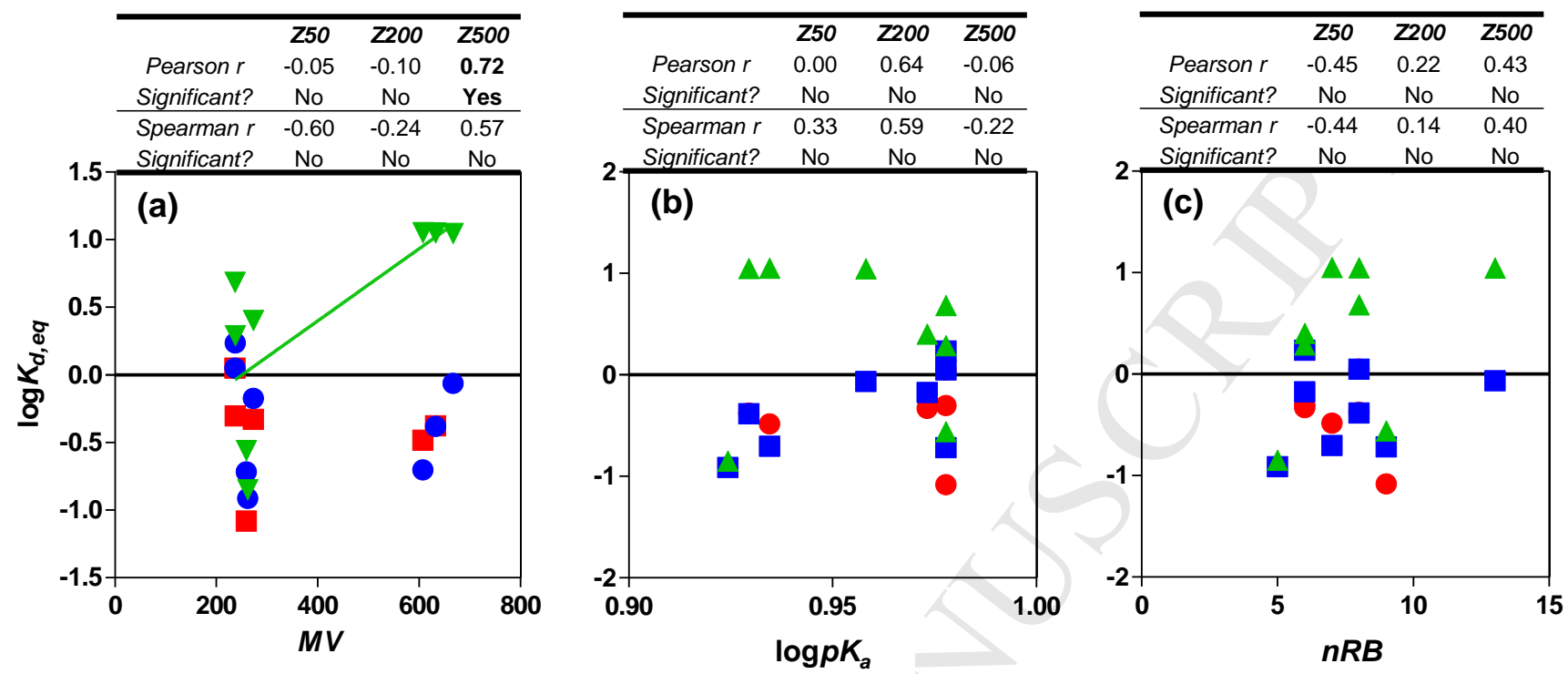

Figure S6. Partitioning coefficients $\left(\log K_{d, e q}\right)$ plotted as a function of the molecular volume $(M V)$, basic dissociation constants $\left(\log p K_{a}\right)$ and the number of rotable bonds $(n R B)$.
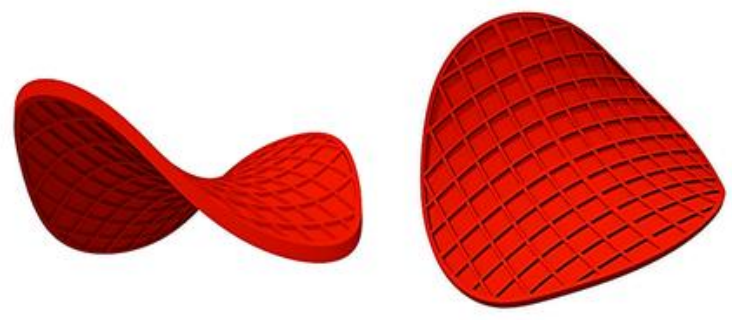

Figure S7. Drawing of Z-carriers used in this study. 


\section{Supplementary Sections}

\section{S1. Biofilm model description}

The model implemented in Aquasim and used in this study is a one-dimensional biofilm model including (i) bulk aqueous phase, (ii) unstirred boundary layer and (iii) biofilm of defined maximum thickness $(H)$, growing on an impermeable solid substratum of surface area $A$. The biofilm compartment consists of pore water and solid biomass, where the fraction of these two phases over the total wet biofilm volume is defined by the porosity $\varepsilon$ and by $1-\varepsilon$, respectively. One-dimensional spatial resolution of the biofilm results in concentrations and density (hence porosity) gradients along one direction only, i.e. over the biofilm depth. The following assumptions were made as to the physical structure of the biofilm, namely (i) the biofilm is at its maximum thickness $H$ during sorption experiments, which is equal to the 50,200 or $500 \mu \mathrm{m}$ depending on the type of Z-carrier; and (ii) the biofilm has constant porosity over its depth, determining constant effective diffusivity of the pharmaceutical in the biofilm. During sorption experiments (from spiking of pharmaceuticals in bulk phase until sorption equilibrium), dynamic conditions are established in the biofilm. Overall, these conditions/assumptions define a one-dimensional dynamic biofilm model. Considering diffusive transport and reaction (sorption/desorption) processes as predominant in the biofilm, the generic microscopic mass balance in the biofilm compartment for the dissolved chemical $C_{L}$ is defined by the following equation (Wanner et al., 2006):

$$
\frac{\partial C_{L}}{\partial t}=D_{b f} \frac{\partial^{2} C_{L}}{\partial z^{2}}+r
$$

where the term $r$ denotes the rates of reaction processes. The specific form of this equation, where reaction processes included sorption to and desorption from biofilm, had already been included in the manuscript (Eq. 2).

As to the bulk aqueous phase, a mass balance can also be established considering that (i) no reaction occurs; and (ii) transfer of spiked pharmaceuticals from bulk aqueous phase to biofilms occurs via diffusive transport through the unstirred boundary layer. Under the assumptions of constant bulk aqueous phase volume $\left(V_{\text {bulk }}\right)$ and no reaction occurring in bulk phase, the mass balance for the dissolved concentration is defined as (Wanner et al., 2006): 
$V_{b u l k} \frac{d C_{L}}{d t}=\frac{A D_{W}}{L_{L}}\left(C_{L, b f}-C_{L, b u l k}\right)$

where $C_{L, b u l k}$ and $C_{L, b f}$ are the dissolved concentrations in bulk phase and at biofilm surface, respectively, A is the bulk-biofilm exchange area and (equivalent to the area covered by biofilm), $D_{W}$ the diffusivity in free water and $L_{L}$ the boundary layer thickness. Given that $C_{L, b f}<C_{L, b u l k}$ at $\mathrm{t}=0$, an outward flux of dissolved pharmaceutical from bulk phase to the biofilm is established.

In this form, the model is a combination of ordinary and partial differential equations. The latter can be solved using the method lines, with discretization of the biofilm compartment into $n$ layers (in this study $n=20$ ), each having the same thickness $\Delta z=H / n$. Layer 1 denotes the top biofilm, while layer 20 denotes the deepest part of the biofilm. This allows for a numerical approximation of the spatial derivate, thus for a simplification of the mathematical model from one-dimensional (with one set of partial differential equations) to zero-dimensional (with $n$ sets of ordinary differential equations, one set for each layer). The mass balance is established in each layer for the two state variables $C_{L}$ and $C_{S}$, where the latter is assumed to undergo negligible diffusive transport within the solid matrix (i.e., cannot be transported upwards or downwards in the biofilm). As described above, the mass balance for $C_{L}$ included sorption, desorption and downward diffusion in each of the biofilm layers, not only in the deepest layer. Given the conditions established in the experiment and its short duration, advective transport of solubles and biofilm detachment were neglected.

The microscopic mass balance in a generic layer (i) for the dissolved mass of pharmaceuticals, considering predominant downward diffusive transport, is written as:

$d m_{L, i} / d t=$ Diffusive mass transfer from layer (i-1) (or bulk phase) - Diffusive mass transfer to layer $(i+1)+$ Desorption from solids in layer $i-$ Sorption to solids in Layer $i$

Diffusive mass transfer from the upper adjacent layer and to the adjacent lower layer (occurring only in pore water phase) defines the connection between different layers of the biofilm, and the "driving force" is given by the difference in dissolved concentration between adjacent layers. Mass balances in different compartments and layers, relevant to the experiments presented in this study, are given below: 
- Bulk aqueous phase

$\mathbf{C}_{\mathrm{L}}: \frac{d C_{L, b u l k}}{d t}=\frac{A D_{W}}{L_{L} V_{b u l k}}\left(C_{L, 1}-C_{L, b u l k}\right)$

$\mathbf{C}_{\mathbf{S}}$ : no sorbed pharmaceuticals are present in bulk phase in the absence of suspended solids

- Layer 1 (top biofilm) $-C_{L}$ and $C_{S}$ in layer 1 are denoted with the subscript ' 1 '

$$
\begin{aligned}
& \mathbf{C}_{\mathbf{L}}: \frac{d C_{L, 1}}{d t}=\frac{A D_{W}}{L_{L} V_{b u l k}}\left(C_{L, b u l k}-C_{L, 1}\right)-\frac{j_{1,2}}{\Delta z}-k_{d e s} K_{d} C_{L, 1} X+k_{d e s} C_{S, 1} \\
& \mathbf{C}_{\mathbf{S}}: \frac{d C_{S, 1}}{d t}=k_{d e s} K_{d} C_{L, 1} X-k_{\text {des }} C_{S, 1}
\end{aligned}
$$

- Layer i (inner biofilm) $-C_{L}$ and $C_{S}$ in layer $i$ are denoted with the subscript ' $i$ '. Layers (i-1) and $(i+1)$ denote the layer above and below layer $\mathrm{i}$.

$$
\begin{aligned}
& \mathbf{C}_{\mathbf{L}}: \frac{d C_{L, 1}}{d t}=\frac{j_{i-1, i}}{\Delta z}-\frac{j_{i, i+1}}{\Delta z}-k_{d e s} K_{d} C_{L, i} X+k_{d e s} C_{S, i} \\
& \mathbf{C}_{\mathbf{S}}: \frac{d C_{S, i}}{d t}=k_{d e s} K_{d} C_{L, i} X-k_{d e s} C_{S, i}
\end{aligned}
$$

- Layer 20 (deep biofilm) $-C_{L}$ and $C_{S}$ in layer 20 are denoted with the subscript ' 20 '

$$
\begin{aligned}
& \mathbf{C}_{\mathbf{L}}: \frac{d C_{L, 20}}{d t}=\frac{j_{19,20}}{\Delta z}-k_{d e s} K_{d} C_{L, 20} X+k_{d e s} C_{S, 20} \\
& \mathbf{C}_{\mathbf{S}}: \frac{d C_{S, 20}}{d t}=k_{d e s} K_{d} C_{L, 20} X-k_{d e s} C_{S, 20}
\end{aligned}
$$

The generic term $j / \Delta z\left(\mathrm{~g} \mathrm{~m}^{-3} \mathrm{~d}^{-1}\right)$ describes the diffusive mass transfer between adjacent layers as a simplification of the second order derivative $D_{b f} \partial^{2} C / \Delta z^{2}$. The two subscripts of the mass flux $j\left(\mathrm{~g} \mathrm{~m}^{-2}\right.$ $\mathrm{d}^{-1}$ ) indicate the layer from which and to diffusive mass transfer occurs, respectively. Based on Fick's first law of diffusion $(j=-D \partial C / \partial z)$, the flux $j$ is a function of the effective diffusivity $D_{b f}$ and of the concentration gradient between adjacent layers, i.e. the driving force for diffusive transport. Further 
details on the numerical methods used to approximate partial differential equations to ordinary differential equations through spatial discretization can be found in Reichert (1994).

Initial conditions for $C_{L}$ and $C_{S}$ in different compartments were established based on measurements and assumptions, i.e.:

Bulk aqueous phase

$C_{L}=C_{L}$ measured at $\mathrm{t}=0$

$C_{S}=0$ (no solids were assumed to be present in the bulk aqueous phase, since the effluent was pre-filtered - see Lines 225-226)

Biofilm (both pore water and solids in each layer $i$ )

$C_{L, i}=0$ (the pore water at $\mathrm{t}=0$ did not contain any mass of pharmaceuticals, since spiking occurred in the bulk aqueous phase)

$C_{S, i}=0$ (the biofilm was pre-washed with tap water overnight to allow for desorption of previously sorbed pharmaceuticals - see also Lines 223-224)

A schematic representation of the system and of the biofilm discretization, as well as of the mass balances in the system and initial conditions for the state variables, is shown in Figure S1.

\section{S2. Biofilm properties}

Biomass dry density in biofilm $\left(\rho_{d}, \mathrm{~g} \mathrm{~cm}^{-3}\right)$ was calculated based on Eq. S10 (Tchobanoglous and Burton 1991; Hu et al., 2013):

$$
\frac{M_{s}}{\rho_{d}}=\frac{M_{f}}{\rho_{f}}+\frac{M_{v}}{\rho_{v}}
$$

where $M_{s}(\mathrm{~g})$ is the dry mass of biofilm solids (expressed as total attached solids, TAS), $M_{f}(\mathrm{~g})$ the dry mass of fixed mineral solids in the biofilm (expressed as total fixed solids, TFS), $\rho_{f}$ the density of fixed solids $\left(=2.5 \mathrm{gTFS} \mathrm{cm}^{-3}\right), M_{v}(\mathrm{~g})$ the dry mass of volatile solids in the biofilm (expressed as total volatile solids, TVS), and $\rho_{v}$ the density of volatile solids $\left(=1 \mathrm{gTVS} \mathrm{cm}^{-3}\right)$.

The biofilm volume not occupied by pores, i.e. including water inside the cells but excluding water outside the cells, was calculated as (Eq. S11): 
$V_{W}=\frac{\frac{M_{s}}{\rho_{d}}}{1-W_{w i}}$

where $W_{w i}$ is the water content inside the cells ( $=80 \%$ of total cell biomass) (Hu et al., 2013; Zhang and Bishop, 1994b). Thus, biofilm porosity (\%) was calculated as (Eq. S12):

$\varepsilon=1-\frac{V_{W}}{V_{b f}}$

where $V_{b f}\left(\mathrm{~m}^{3}\right)$ is the total biofilm volume (volume of wet biofilm including pore water volume, determined from nominal surface area and biofilm thickness of each Z-carrier type). The pore water volume $\mathrm{V}_{\mathrm{PW}}\left(\mathrm{m}^{3}\right)$ was eventually determined as (Eq. S13):

$V_{P W}=\varepsilon \cdot V_{b f}=V_{b f}-V_{W}$

Finally, the biofilm density (gTAS $\mathrm{m}^{-3}$ ) was calculated as (Eq. S14):

$\rho=\frac{M_{s}}{V_{b f}}$

We note that biofilm density $\rho$ (Eq. S14) denotes the mass of (microbial) biomass per volume of wet biofilm (i.e., defines a concentration within the biofilm), while the dry biofilm density $\rho_{d}$ denotes the weight of dry biofilm per volume of dry biofilm (i.e., defines a true density).

The thickness of the boundary layer, $L_{L}(\mu \mathrm{m})$, was assumed to be equal to $10 \mu \mathrm{m}$ for all the Z-carriers. $L_{L}$ can be estimated, based on fluid dynamics principles, as a function of the characteristic length of the carrier $L_{C}$ (the flow-through radius of the biofilm carrier minus the biofilm thickness) and the nondimensional Sherwood number (Boltz et al., 2011). When considering Z-carriers design, $L_{C}$ is minimized as most of the interstitial space is occupied by the biofilm (Torresi et al., 2016). Thus, $L_{L}$ was selected by considering the lowest value reported in literature (Brockmann et al., 2008; Joss et al., 2004). It is likely that the high flow rate of nitrogen sparging during batch experiments may have further minimized $L_{L}$, as previously considered (Wicke et al., 2007). Furthermore, comparable $L_{L}$ values have been used for fate modelling of illicit drugs (having similar $D_{W, i}$ with the chemicals assessed in this study) in sewer biofilms (Ramin et al., submitted). 


\section{S3. Derivation of the adjusted partition coefficient (Equation 5)}

Based on mass conservation principles, the mass of pharmaceuticals spiked at $\mathrm{t}=0$ in the bulk phase is equivalent to the total mass at the end of sorption experiments. Hence, the following mass balance can be written (in the absence of any biological or abiotic degradation of pharmaceuticals):

Mass spiked in bulk phase $(\mathrm{t}=0)=$ Remaining mass in bulk phase + Mass dissolved in pore water + + Mass sorbed to biofilm solids

The above mass balance can be translated in the following equation:

$$
C_{L, 0} V_{b u l k}=C_{L, e q} V_{b u l k}+C_{L, e q} V_{P W}+C_{S, e q}^{*} M_{X, \text { biomass }}
$$

where $C_{L, O}$ and $C_{L, e q}\left[\mu \mathrm{g} \mathrm{L}^{-1}\right]$ are the dissolved pharmaceuticals concentrations at $\mathrm{t}=0$ and at equilibrium, respectively; $C_{S, e q} *\left[\mu \mathrm{g} \mathrm{g}^{-1}\right]$ is the sorbed concentration and the superscript '*' is used to distinguish it from $C_{S, e q}\left[\mu \mathrm{g} \mathrm{L}{ }^{-1}\right]$ as defined in the main text; $V_{b u l k}$ and $V_{P W}[\mathrm{~L}]$ are the volumes of bulk aqueous phase and pore water, respectively; and $M_{X, \text { biomass }}[\mathrm{g}]$ is the mass of solids in the system.

The mass of solids can be defined as the product of the concentration of solids in the system and the total volume of the system:

$$
M_{X, \text { biomass }}=X_{\text {biomass }}\left(V_{\text {bulk }}+V_{b f, \text { wet }}\right)
$$

where $X_{\text {biomass }}\left[\mathrm{g} \mathrm{L}^{-1}\right]$ denotes the concentration of solids as defined in the manuscript text $\left(0.8 \mathrm{~g} \mathrm{~L}^{-1}\right)$ and $V_{b f, w e t}[\mathrm{~L}]$ is the volume of wet biofilm (= surface area of $\mathrm{Z}$ carriers $\cdot$ biofilm thickness, also equal to the sum of pore water volume and volume occupied by solids in biofilm).

Hence, the last term of the sum can be rearranged as:

$$
C_{S, e q}^{*} M_{X, \text { biomass }}=C_{S, e q}^{*} X_{\text {biomass }}\left(V_{b u l k}+V_{b f, \text { wet }}\right)=C_{S, e q}\left(V_{b u l k}+V_{b f, \text { wet }}\right)
$$

where $C_{S, e q}\left[\mu \mathrm{g} \mathrm{L}^{-1}\right]$ is the sorbed concentration of pharmaceuticals as defined in the main text (e.g., Eqs. 3 and 4$)$.

By rearranging the mass balance, we can write:

$$
C_{S, e q}\left(V_{b u l k}+V_{b f, w e t}\right)=C_{L, 0} V_{b u l k}-C_{L, e q} V_{b u l k}-C_{L, e q} V_{P W}
$$

and it follows that:

$$
C_{S, e q}=C_{L, 0} V_{b u l k} /\left(V_{b u l k}+V_{b f, w e t}\right)-C_{L, e q}\left(V_{b u l k}+V_{P W}\right) /\left(V_{b u l k}+V_{b f, w e t}\right)
$$


Eventually, the adjusted partition coefficient $K_{d}$ (accounting for the pharmaceutical concentration dissolved in pore water) can be written as:

$$
K_{d}=C_{S, e q} /\left(C_{L, e q} X_{\text {biomass }}\right)=\left\lfloor C_{L, 0} V_{b u l k} /\left(V_{b u l k}+V_{b f, w e t}\right)-C_{L, e q}\left(V_{b u l k}+V_{P W}\right) /\left(V_{b u l k}+V_{b f, w e t}\right)\right] /\left(C_{L, e q} X_{\text {biomass }}\right)
$$

which is also presented as Equation 5 in the main manuscript text.

\section{S4. Proposed empirical correlation for effective diffusivity coefficient $f$}

An exponential equation was first used to correlate $f$ with $\log K_{O W}$ at each biofilm thickness (Fig. S3). Secondly, the intercept $\left(\mathrm{y}_{0}\right)$, the asymptotic coefficient $\mathrm{b}$ (corresponding to the maximum $\log \mathrm{K}_{\mathrm{OW}}$ ) and the slope (k) (see Fig. S4) estimated separately for Z50, Z200 and Z500 were plotted against biofilm thickness (Fig. S4, a-c). While no trend was observed for $\mathrm{y}_{0}$ and $\mathrm{b}$ with biofilm thickness, a second exponential equation was used to correlate values of slope $(\mathrm{k})$ of the three biofilms with biofilm thickness. The obtained relationship is presented in Eq. S21

$$
f=\frac{1}{488 \cdot e^{-0.0072 L_{F}}} \ln \left(\frac{-12.7-\log K_{o w, \max }}{\log K_{o w}-\log K_{o w, \max }}\right)
$$

where $L_{F}$ is the biofilm thickness $(\mu \mathrm{m})$ and $\log K_{o w, \max }$ is the asymptotic $\log K_{o w}$ which approximate the one reported for the targeted compounds in this study. 


\section{References}

Beyenal, H., Seker, S., Tanyolaç, A., 1997. Diffusion Coefficients of Phenol and Oxygen in a Biofilm of Pseudomonas putida. AIChE J. 43, 243-250.

Boltz, J.P., Morgenroth, E., Brockmann, D., Bott, C., Gellner, W.J., Vanrolleghem, P.A., 2011. Systematic evaluation of biofilm models for engineering practice: components and critical assumptions. Water Sci. Technol. 64, 930.

Brockmann, D., Rosenwinkel, K.H., Morgenroth, E., 2008. Practical identifiability of biokinetic parameters of a model describing two-step nitrification in biofilms. Biotechnol. Bioeng. 101, 497514.

Hayduk, W., Laudie, H., 1974. Prediction of diffusion coefficients for nonelectrolytes in dilute aqueous solutions. AIChE J. 20, 611-615.

Hinson, R.K., Kocher, W.M., 1996. Model for effective diffusivities in aerobic biofilms 122, 10231030.

Horn, H., Morgenroth, E., 2006. Transport of oxygen, sodium chloride, and sodium nitrate in biofilms. Chem. Eng. Sci. 61, 1347-1356.

Hu, M., Zhang, T.C., Stansbury, J., Neal, J., Garboczi, E.J., 2013. Determination of Porosity and Thickness of Biofilm Attached on Irregular-Shaped Media. J. Environ. Eng. 139, 923-931.

Joss, A., Andersen, H., Ternes, T., Richle, P.R., Siegrist, H., 2004. Removal of estrogens in municipal wastewater treatment under aerobic and anaerobic conditions: consequences for plant optimization. Appendix: Diffusive mass transfer across the boundary layer and inside the floc. Environ. Sci. Technol. 38, 3047-55.

Piculell, M., Welander, P., Jönsson, K., Welander, T., 2016. Evaluating the Effect of Biofilm Thickness on Nitrification in Moving Bed Biofilm Reactors 37, 732-743.

Ramin, P., Libonati Brock, A., Causanilles, A., Valverde-Pérez, B., Emke, E., de Voogt, P., Polesel, F., Plósz, B.G. Transformation and sorption of illicit drug biomarkers in sewer biofilms. Submitted to 
Environ. Sci. Technol.

Reichert, P., 1994b. Concepts underlying a computer program for the identification and simulation of aquatic systems. Swiss Federal Institute for Environmental Science and Technology (EAWAG), Dübendorf, Switzerland.

Schwarzenbach, R.P., Gschwend, P.M., Imboden, D.M., 2003. Environmental Organic Chemistry (2 $^{\text {nd }}$ edition). John Wiley \& Sons, Inc., Hoboken, NJ, US.

Sitaraman, R., Ibrahim, S.H., Kuloor, N.R., 1963. A generalized equation for diffusion of liquids. J. Chem. Eng. Data 8, 198-201.

Tchobanoglous G., Burton F., Stensel H., Wastewater Engineering Treatment and Reuse, 4th ed., Metcalf and Eddy, Inc., McGraw-Hill Company, New York, 2003.

Torresi, E., Fowler, J.S., Polesel, F., Bester, K., Andersen, H.R., Smets, B.F., Plosz, B.G., Christensson, M., 2016. Biofilm thickness influences biodiversity in nitrifying MBBRs Implications on micropollutant removal. Environ. Sci. Technol. 50, 9279-9288.

Trapp, S., Matthies, M., 1998. Transport and Transformation of Compounds in Soil, in: Chemodynamics and Environmental Modeling. Springer-Verlag.

Wanner, O., Eberl, H.J., Morgenroth, E., Noguera, D.R., Picioreanu, C., Rittmann, B.E., van Loosdrecht, M.C.M., 2006. Mathematical modeling of biofilms. IWA Publishing.

Wicke, D., Bockelmann, U., Reemtsma, T., 2007. Experimental and modeling approach to study sorption of dissolved hydrophobic organic contaminants to microbial biofilms. Water Res. 41, 2202-2210.

Wilke, C.R., Chang, P., 1955. Correlation of diffusion coefficients in dilute solutions. AIChe J. 1, 264270.

Zhang, T.C., Bishop, P.L., 1994a. Evaluation of tortuosity factors and effective diffusivities in biofilms. Water Res. 28, 2279-2287.

Zhang, T.C., Bishop, P.L., 1994b. Density, porosity, and pore structure of biofilms. Water Res. 28, 
2267-2277.

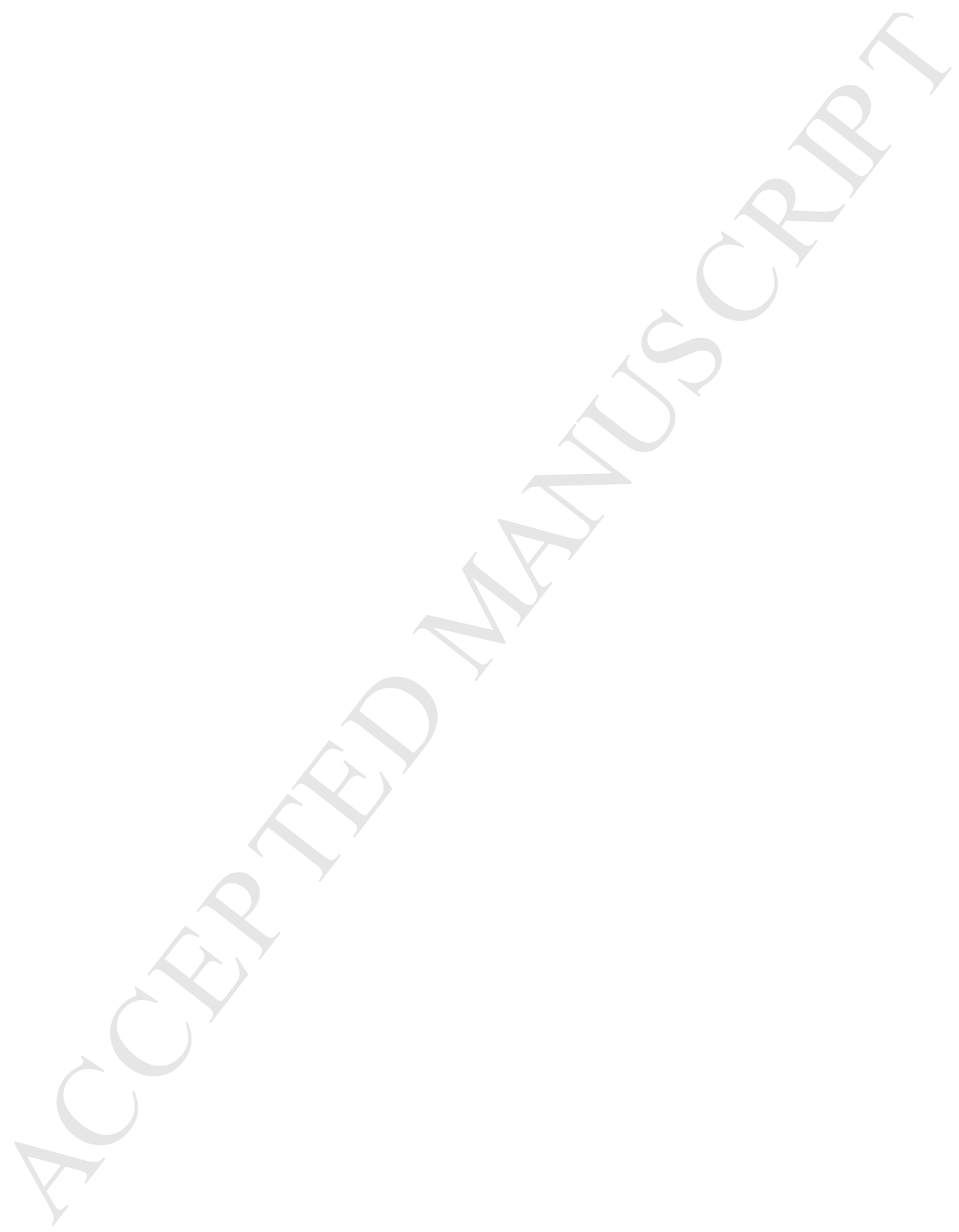

